\title{
Sediment Transport and Morphological Response to Nearshore Nourishment Projects on Wave-Dominated Coasts
}

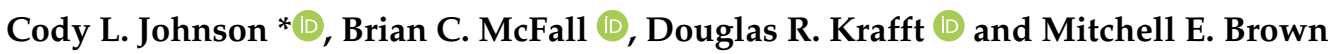 \\ Coastal and Hydraulics Laboratory, U.S. Army Engineer Research and Development Center, \\ Vicksburg, MS 39180, USA; Brian.C.McFall@usace.army.mil (B.C.M.); Douglas.R.Krafft@usace.army.mil (D.R.K.); \\ Mitchell.E.Brown@usace.army.mil (M.E.B.) \\ * Correspondence: Cody.L.Johnson@usace.army.mil; Tel.: +1-601-634-2552
}

Citation: Johnson, C.L.; McFall, B.C.; Krafft, D.R.; Brown, M.E. Sediment Transport and Morphological Response to Nearshore Nourishment Projects on Wave-Dominated Coasts. J. Mar. Sci. Eng. 2021, 9, 1182. https://doi.org/10.3390/jmse9111182

Academic Editor: Carlos Daniel Borges Coelho

Received: 4 October 2021

Accepted: 25 October 2021

Published: 27 October 202

Publisher's Note: MDPI stays neutral with regard to jurisdictional claims in published maps and institutional affiliations.

Copyright: (c) 2021 by the authors. Licensee MDPI, Basel, Switzerland. This article is an open access article distributed under the terms and conditions of the Creative Commons Attribution (CC BY) license (https:// creativecommons.org/licenses/by/ $4.0 /)$

\begin{abstract}
Nearshore nourishments are constructed for shoreline protection from waves, to provide sediment nourishment to the beach profile, and to beneficially use dredged sediment from navigation channel maintenance. However, it is poorly understood how placement morphology and depth influence nearshore processes operated on wave-dominated coasts. This study investigates the wave fields, sediment transport, and morphological response to three common nearshore nourishment shapes, nearshore berm (elongated bar), undulated nearshore berm, and small discrete mounds, with numerical experiments utilizing the Coastal Modeling System. The nourishments are placed in depths between $3 \mathrm{~m}$ and $7 \mathrm{~m}$ with a volume of approximately 100,000 $\mathrm{m}^{3}$ and between $400 \mathrm{~m}$ and $1000 \mathrm{~m}$ in alongshore length. Numerical experiments are carried out in three distinct coastal settings with representative wave climates and geomorphology. Simulation results indicate that shallower, more continuous berms attenuate the most wave energy, while deeper, more diffuse placements retain more sediment. Results from this study improve the understanding of nearshore nourishment shapes and can support decision makers identifying the most appropriate construction technique for future nearshore nourishment projects.
\end{abstract}

Keywords: nearshore nourishment; wave dissipation; nearshore sediment transport; coastal hydrodynamic modeling

\section{Introduction}

Sandy beaches are a natural or nature-based feature (NNBF) that serve a crucial societal, cultural, economic, and environmental role [1] but typically require periodic maintenance through sand nourishment. Nourishment projects can be on the subaerial beach or in the nearshore. Nearshore nourishment projects are commonly completed around the globe. In the United States (U.S.), the U.S. Army Corps of Engineers currently place more than 7.7 million $\mathrm{m}^{3}$ in the nearshore annually [2]. Nourishments in the U.S. are constructed in a range of dimensions and conditions, with placement depths ranging from $1.5 \mathrm{~m}$ to $26 \mathrm{~m}$, nourishment volumes between $18,000 \mathrm{~m}^{3}$ to $14,300,000 \mathrm{~m}^{3}$, and heights of $0.5 \mathrm{~m}$ to $9 \mathrm{~m} \mathrm{[2].} \mathrm{Projects} \mathrm{that} \mathrm{place} \mathrm{sediment} \mathrm{in} \mathrm{the} \mathrm{nearshore} \mathrm{have} \mathrm{many} \mathrm{names,} \mathrm{including}$ nearshore nourishment, profile nourishment, nearshore placement, littoral placement, or shoreface nourishment. When the sediment is intentionally placed as an artificial sandbar or mound, it is called a nearshore berm. Regardless of the name, the projects nourish the beach profile by placing sediment in the nearshore zone.

Nearshore nourishment projects can be constructed by beneficially using dredged sediment from navigation channels, and they can be used as a flood risk reduction method. Goals for these projects often include dissipating wave energy farther from the shoreline, keeping sediment in the littoral system, and nourishing the beach profile with minimal environmental impacts. Previous nearshore nourishment research initiatives have focused on the transport rate and direction of the sediment placed in the nearshore [3-6], and the morphodynamic response to the placed sediment [7-9]. Different construction methods 
will place sediment differently in the nearshore and thereby create nourishment features with different geometries. There has been minimal effort applied to understanding how the geometry of the nearshore nourishment features influence the sediment transport and nearshore morphological change.

Constructing a linear nearshore berm is a nourishment strategy that has been researched with field studies [10], physical models [11-13], and numerical tools and models [9,13-22]. Linear berms can be constructed by placing sediment with a hydraulic pipeline or by bottom dumping hoppers or scows [23]. Undulated nearshore berms, i.e., shore parallel berms with sinusoidal variation in berm height, may be used to create a shoreline response of multiple small cusps to minimize the environmental impact to beach dwelling species, e.g., filter feeders such as the Emerita talpoida (mole crab) and Donax variabilis (coquina clam) [24,25]. Many nearshore nourishment projects constructed with hopper dredges beneficially use dredged navigation channel sediment and place the sediment in small discrete mounds in a large placement area within the littoral zone [26]. This typically results in an approximately random distribution of individual mounds in the nearshore. This project investigates how the nearshore nourishment shape, such as these, and placement depth influence the sediment transport and morphodynamics on wave-dominated coasts when forced by different wave climates. Other factors contributing to nearshore circulation, such as wind stress and tides, have been neglected in order to isolate the dominant processes of wave-driven sediment transport.

In this section, a brief introduction to nearshore nourishments and the current work is provided with references to the relevant literature. The manuscript is structured as follows. Section 2 explains the methodology of the study, including the Coastal Modeling System (CMS), creation of numerical experiments, and the data analysis techniques. Section 3 details the results of the numerical experiments, and an analysis of the simulated data is presented. Section 4 provides a discussion of the analysis and model results with emphasis on the practice of nearshore nourishment design. Section 5 summarizes the work with an itemized list of conclusions.

\section{Materials and Methods}

\subsection{Idealized Scenarios}

\subsubsection{Regional Study Sites}

In order to realistically approximate the conditions of actual nearshore nourishments, model inputs were derived from historical project sites. These sites, located within three contrasting coastal regions of the U.S., were selected to represent a range of wave climates and nearshore geomorphologies. The sites selected were South Padre Island, TX (SP); Vilano Beach, FL (VB); Ogden Dunes, IN (OD), which represent the Gulf of Mexico, East Coast, and Great Lakes regions, respectively (see Figure 1). These locations have been the site of nearshore placements in the past, as well as data collection efforts, which further facilitated model set up. Bathymetry and wave climate data were required from each site to create inputs for each model scenario. Overall, OD has less energetic waves and a steeper offshore profile than the other sites and is situated within a large interior lake (Lake Michigan); SP has more energetic waves than OD, but it has shorter wave periods than VB due to wave generation occurring within the Gulf of Mexico; VB has longer period waves originating within the south Atlantic Ocean and is the most energetic of the three sites. Additional wave climate details are described in Section 2.1.4 and the reader is referred to Figlus et al. (2021) [27], Brutsché et al. $(2017,2019)$ [7,28], and Young et al. (2020) [26] for more site characterization at $\mathrm{SP}, \mathrm{VB}$, and $\mathrm{OD}$, respectively. 


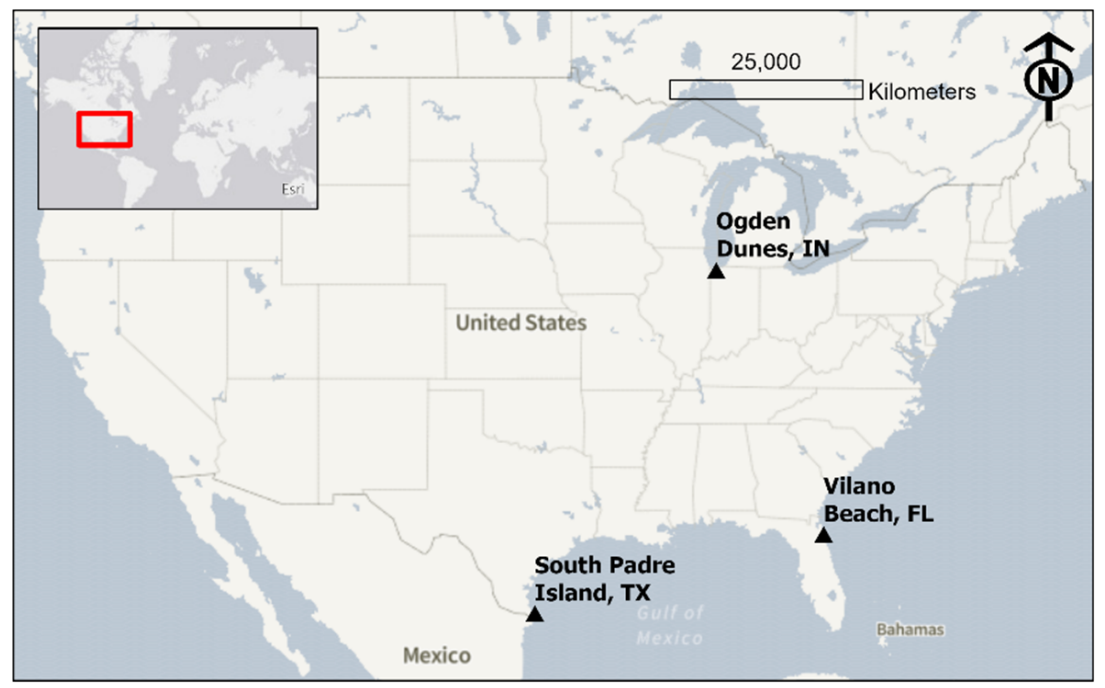

Figure 1. Site locations used in model set up.

\subsubsection{Nearshore Profile Morphology}

An idealized bathymetry for each site is created by fitting the underlying nearshore bathymetry to the equilibrium profile defined by Komar and McDougal (1994) as

$$
h=B\left(1-e^{-k x}\right),
$$

where $h$ is the depth, $B$ is a parameter, $k$ is the profile's decay coefficient, and $x$ is the distance from the shoreline. The slope of the equilibrium profile,

$$
\frac{d h}{d x}=k B e^{-k x},
$$

can be used to estimate $B$. Setting $x=0 \mathrm{~m}$ in Equation (2) yields the shoreline slope, $S_{0}=k B$, which was estimated from grain size data [10] and Wave Information Studies (WIS) [29] wave height using the relationships proposed by McFall (2019) [30]. This reduces Equation (1) to a single parameter optimization problem, $h=\frac{S_{0}}{k}\left(1-e^{-k x}\right)$, where $k$ was determined by fitting Equation (1) to a set of shore-aligned, shore-normal bathymetric profiles.

The bathymetric profile data was collected by sampling shore-normal transects of the National Oceanographic and Atmospheric Administration's National Centers for Environmental Information (NCEI) digital terrain models for the study sites. This data was then aligned so that $z=M S L$ corresponded to $x=0 \mathrm{~m}$. See Figure 2 for the sampled bathymetry data and resulting equilibrium profiles for each study site. It can be seen that, while some features of the profile data are not captured by the equilibrium profile, the general nearshore morphology is well represented and displays inter-regional variability. The assumption of a monotonic profile model neglects bar/trough features that are evident in the nearshore profile data and would naturally generate wave transformation. This assumption is justified in order to independently study wave transformation and sediment transport processes introduced by the nearshore nourishments. The equilibrium profiles were replicated in the alongshore to create alongshore uniform beaches for model input. 


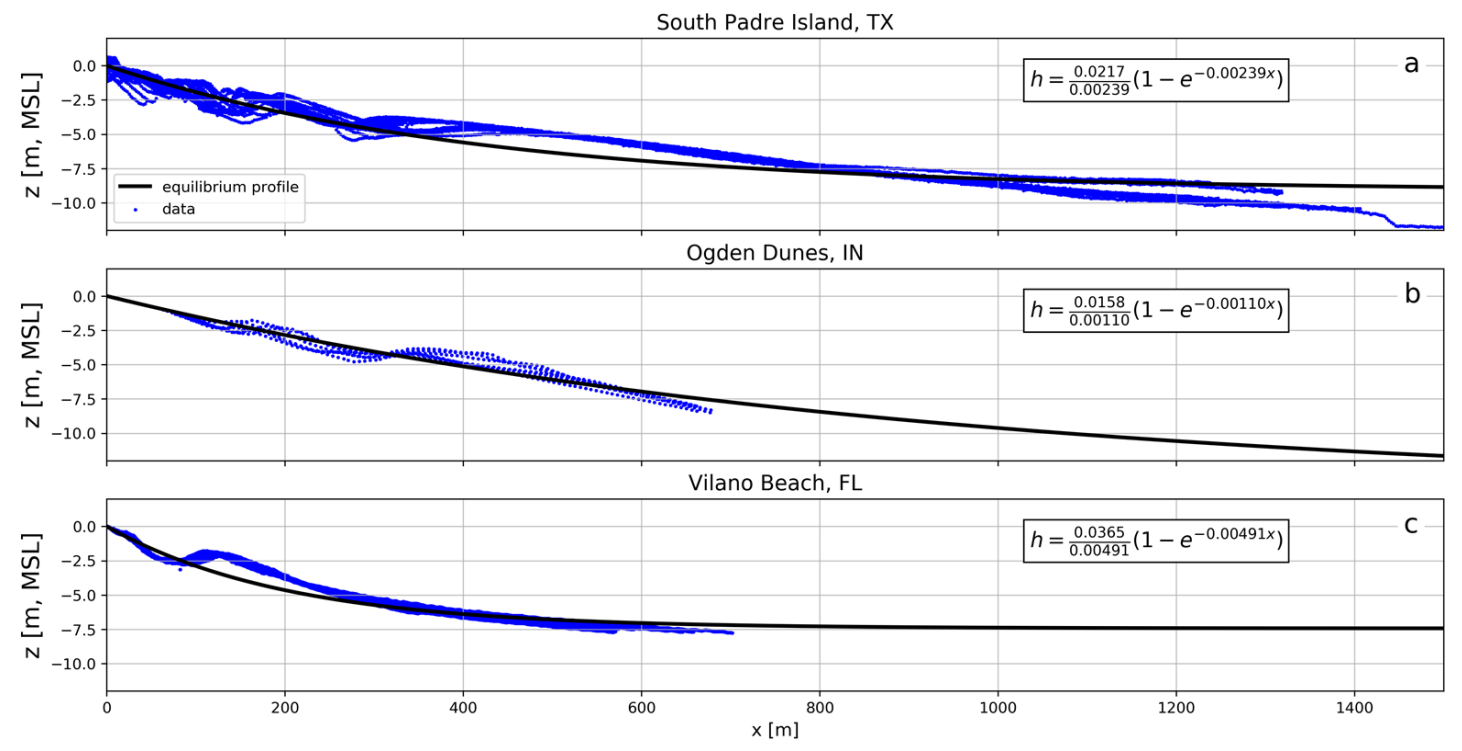

Figure 2. Nearshore bathymetry data (blue markers) and fitted equilibrium profile (solid black line) for the study sites. (a) Data and equilibrium profile for South Padre Island; (b) Ogden Dunes; and (c) Vilano Beach.

\subsubsection{Nearshore Nourishment Shapes}

Three nearshore nourishment shapes were investigated, a linear berm (LB), an undulated berm (UB), and a uniform distribution of discrete mounds (DM). The linear berm was alongshore uniform, except for the end caps that smoothly graded into the equilibrium profile. The undulated berm was similar to the linear berm, but the berm crest height $\left(h_{b}\right)$ oscillated in the alongshore direction following a cosine function. Thus, at its highest point the UB crest was equal to the LB, but dips to half the LB crest height at its lowest point with a wave length of $160 \mathrm{~m}$. The discrete mounds were constructed by uniformly distributing two-dimensional Gaussian functions within an area with crests spaced $25 \mathrm{~m}$ apart. Each nearshore nourishment shape was investigated centered at three different depths per equilibrium profile (i.e., region), $3 \mathrm{~m}, 5 \mathrm{~m}$, and $7 \mathrm{~m}$. The nourishment shapes and placement depths were chosen to represent nearshore nourishment construction practice observed in the field [6].

The combination of nourishment shape, depth, and region, plus one case per equilibrium profile without a nearshore nourishment to function as a control, resulted in a total of 30 numerical experiments. The nearshore placement volumes were held approximately constant at $100,000 \mathrm{~m}^{3}$ to mitigate the influence of the variability on inter-comparisons. The geometric range of the nourishments (bed slope and curvature, crest height, etc.) introduced some variability in the absolute dimensions of the nearshore placements. Thus, the alongshore length and cross-shore width of the linear/undulated berms and the discrete mounds' footprints necessarily varied to a small degree between cases

The berm's cross-shore shape itself was derived from survey data of a nearshore berm constructed at Ft. Myers Beach, FL [23]. A Gaussian function,

$$
f(x)=\alpha \exp \left[\frac{-\left(x-x_{b}\right)^{2}}{2 \sigma^{2}}\right],
$$

where $x_{b}$ is the cross-shore distance to the berm crest, and $\alpha$ and $\sigma$ are the scale and width parameters, respectively, used to approximate the berm as it intersected the underlying equilibrium profile. To generate congruent berm shapes across the range of cases, the berm's height above the bed $\left(h_{b}\right)$ was held constant for each berm type, and the ratio of the Gaussian function's amplitude $\left(\alpha=h_{b}+\epsilon\right)$ to its width $(\sigma)$ was also held constant (see Figure 3). For each Gaussian curve generated, an algorithm incremented $\epsilon$, then calculated $\alpha$ and $\sigma$, which continued until the seaward tail of the Gaussian mound was less than $1 \mathrm{~mm}$ 
from the equilibrium profile. The result was a smooth equilibrium profile exhibiting berms with similar geometric properties. See Figure 4 for a demonstration of the SP profile with the three LBs placed at depths of $3 \mathrm{~m}, 5 \mathrm{~m}$, and $7 \mathrm{~m}$. Note that the initial depth of the berm crest, $F_{b}$, is the same between profiles, but the berm's cross-sectional area may be somewhat smaller or larger depending on the profile's local slope and curvature. The discrete mound cases had smaller $h_{b}$ in order to approximate a hopper dredge capacity of $360 \pm 60 \mathrm{~m}^{3}$.

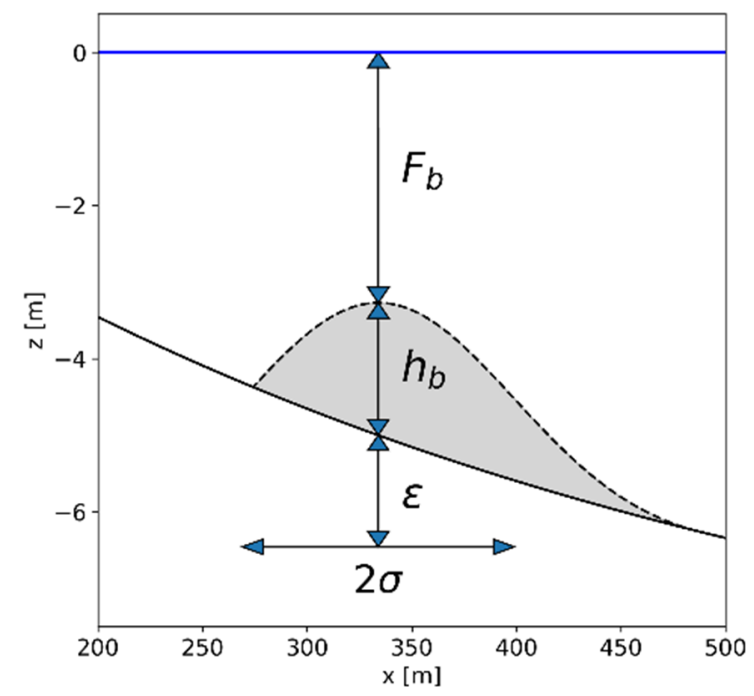

Figure 3. Cross-shore profile of idealized nearshore berm.

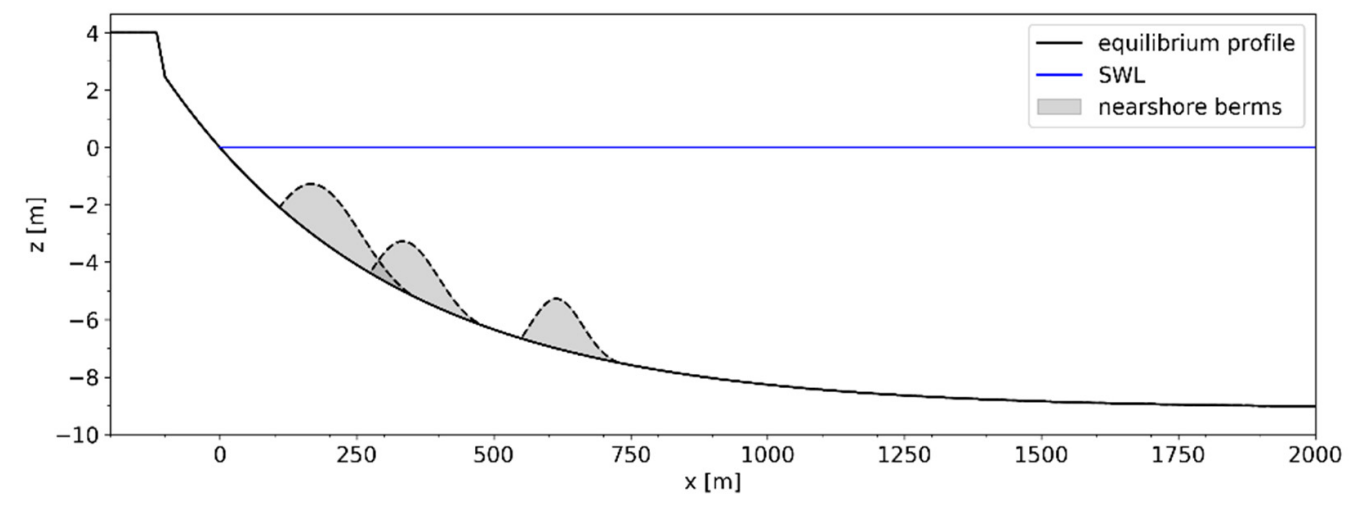

Figure 4. Cross-shore profile of SP linear berms.

\subsubsection{Wave Climate}

An incident wave field was used to drive the nearshore circulation and sediment transport. Since the goal was to provide realistic estimates of nearshore nourishment performance, real-world waves were required in contrast to schematized conditions. The WIS database provides long-term hindcast time-series of bulk wave parameters generated from a third-generation, phased-averaged wave model and was selected to create input wave boundary conditions. WIS employs WAVEWATCH III to simulate wave energy transformation along the U.S. coastline and outputs results at regularly spaced locations. The stations used were 73,020,94,001, and 63,417 with nominal depths of $36 \mathrm{~m}, 17 \mathrm{~m}$, and $19.5 \mathrm{~m}$ for the SP, OD, and VB scenarios, respectively. The wave parameters were shoaled to profiles' offshore boundary depths using Snell's law. Further, the wave angles were rotated from the geographic coordinate system of the WIS data to the idealized models' coordinate system

To obviate the need to select a particular time span to simulate, a method of generating random, realistic time-series of wave conditions from WIS data was adopted using Markov chain models [31]. The synthetic time-series retained the essential statistical properties 
of each site's sea state, i.e., the mean and variance of the significant wave height, peak period, and mean wave direction. Three-dimensional Markov chain models of these bulk parameters were generated from the 40 year hindcast records at each site. The fall and winter months were chosen to drive the model as they statistically exhibit more frequent and larger storm events. This may result in more sediment transport seaward than would occur if the summer/spring months were included in the simulations. Additionally, the historical projects at these sites were constructed in the summer, exposing the nourishment to fall and winter waves following construction. See Figures 5 and 6 for a comparison of the modeled and WIS hindcast wave height probability density functions (PDF) and an example realization of the VB Markov model, respectively.
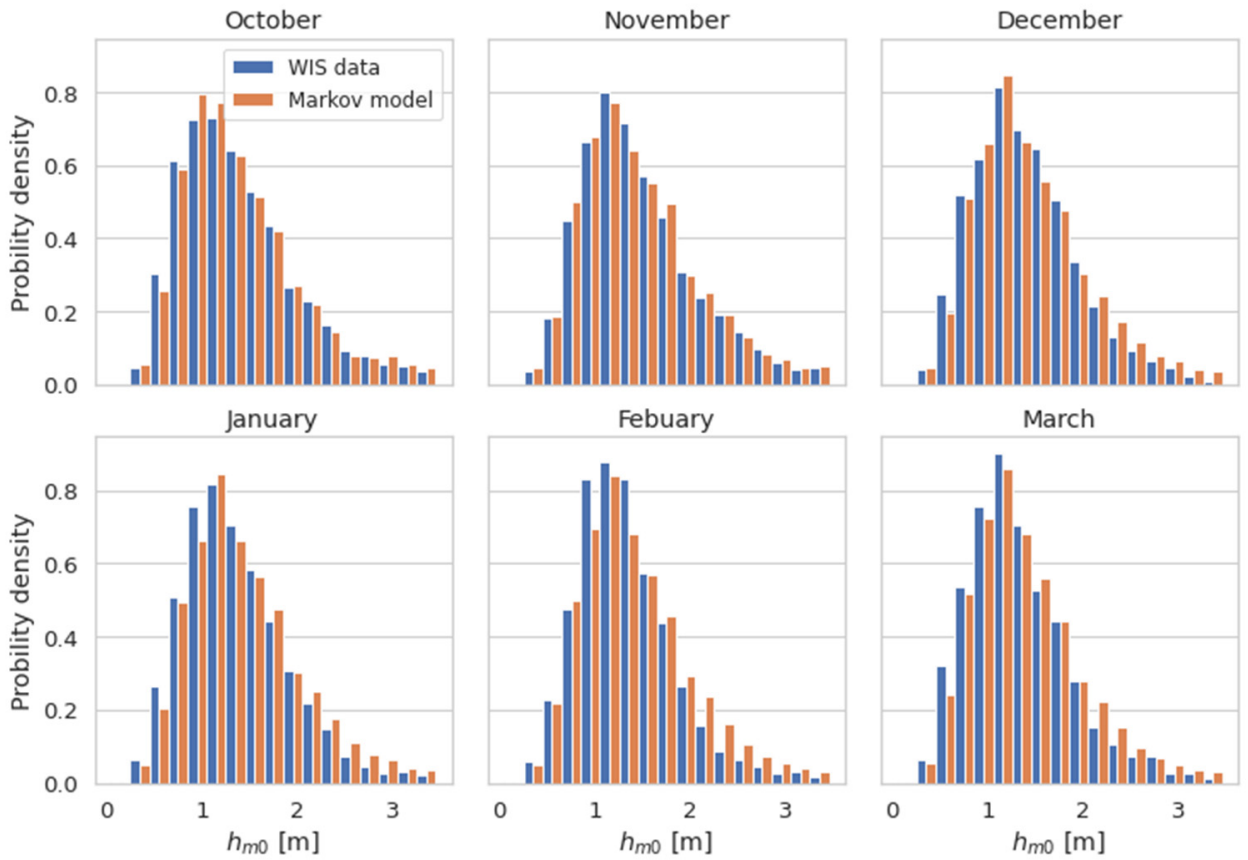

Figure 5. Monthly wave height PDFs of the WIS (blue) and Markov chain model results (orange) used as input to the VB scenario. Starting at the upper left, and from left to right, the panels show PDFs for October through March.
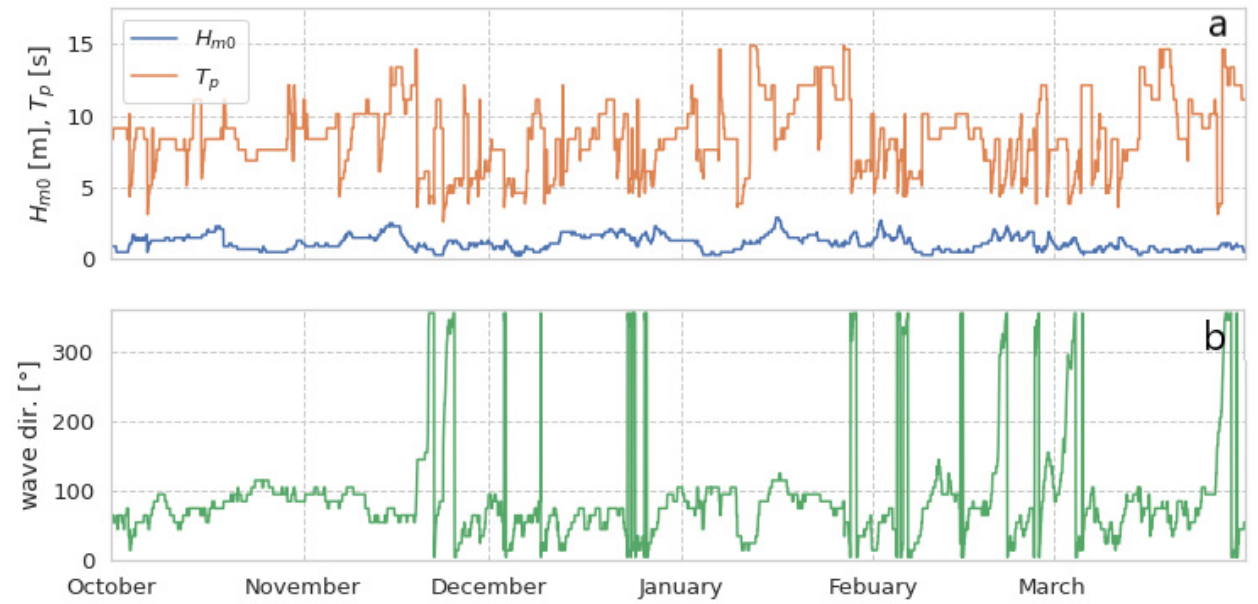

Figure 6. Realization of the Markov chain model for VB. (a) Zero-moment wave height (blue line) and peak period (orange line); (b) wave direction (green line).

The wave climates differed between the regions to a large extent (see Table 1). Wave heights and periods at OD were the smallest, where on average zero-moment wave heights 
$\left(H_{m 0}\right)$ were less than $0.5 \mathrm{~m}$. This is contrasted with the other two regions, which had mean wave heights above $1 \mathrm{~m}$. While both SP and VB had large maximum wave heights, and comparable mean significant wave heights, their mean peak periods $\left(T_{p}\right)$ were different.

Table 1. Statistics of regional wave climates, including the maximum zero-moment wave height, the mean (and standard deviation) zero-moment wave height, and the mean (and standard deviation) peak period.

\begin{tabular}{cccc}
\hline Region & Max. $\boldsymbol{H}_{m 0}(\mathrm{~m})$ & Mean $\left(\right.$ std.) $\boldsymbol{H}_{\boldsymbol{m} 0}(\mathrm{~m})$ & Mean $(\mathbf{s t d}.) \boldsymbol{T}_{\boldsymbol{p}}(\mathrm{s})$ \\
\hline SP & 4.16 & $1.11(0.48)$ & $6.3(1.6)$ \\
VB & 4.17 & $1.45(0.63)$ & $9.5(2.6)$ \\
OD & 3.22 & $0.47(0.44)$ & $3.8(1.7)$ \\
\hline
\end{tabular}

\subsection{Numerical Model}

\subsubsection{The Coastal Modeling System}

The Coastal Modeling System (CMS) was employed to simulate the nearshore nourishment evolution and wave fields. The CMS consists of a combined suite of $2 \mathrm{DH}$ modules for flow, waves, and sediment transport with morphology change [32,33]. The CMS began as a class project in 1994 at Florida Institute of Technology and improved over several years to a full-fledged two-dimensional (2DH) circulation model named M2D [34,35]. The Coastal Inlets Research Program added many more capabilities to M2D, including sediment transport and simplified 2DH salinity, added an implicit solution scheme to the existing explicit offering, integrated a phase-averaged wave model, and eventually renamed the model from M2D to the Coastal Modeling System to represent its intended use in nearshore coastal regimes.

CMS-Flow is solved with numerical computations of the mass, momentum, and sediment transport equations on either a Cartesian or Quadtree grid and with either an implicit or explicit solution scheme using a finite-volume method. CMS-Wave is a steady-state, phase-averaged, spectral wave module that computes wave height, direction, and period, wave dissipation, and wave radiation stresses $[36,37]$ and includes wave transformation processes such as refraction, diffraction, reflection, shoaling, and wave breaking. The link between the two modules is two-way. CMS-Wave calculated radiation stresses and wave dissipation values are passed to CMS-Flow to impose wave action on the currents. The wave-modified currents are then used to force sediment transport with one of several transport algorithms, as chosen prior to simulation start. Once CMSFlow calculates the resulting hydrodynamics and sediment transport, the wave-modified currents and updated depths due to sediment transport are passed to CMS-Wave to compute the waves at the next time interval, as designated by a user-defined parameter, and therefore completes the two-way interaction between wave and flow processes.

\subsubsection{Computational Domain}

Two computational grids were created for the hydrodynamic/sediment transport/ morphology change model (CMS-Flow) and the phase-averaged wave model (CMS-Wave), which were used for all the simulations. The grids were used to couple the waves and hydrodynamics as described in Section 2.2.1, but all simulated results were output on the CMS-Flow grid. This was done to facilitate post-processing and ensure commensurability of the simulation results.

Overall, the computational domains extended $1800 \mathrm{~m}$ in the alongshore and $2180 \mathrm{~m}$ in the cross-shore (see Figure 7 for a diagram of the computational grids). An area of interest (AoI) was delineated within the domain. The AoI used a uniform grid spacing of $3 \mathrm{~m}$. The AoI covered the extents of each nearshore nourishment across the regions, depths, and morphologies. The CMS-Flow grid utilized Quadtree refinement [37] to transition from a resolution of approximately $50 \mathrm{~m}$ at the offshore boundary to that of the AoI, while the CMS-Wave grid smoothly refined a Cartesian grid from a resolution of $100 \mathrm{~m}$ at the 
offshore to the AoI [38]. The minimum grid resolution was chosen to resolve the individual discrete mounds.
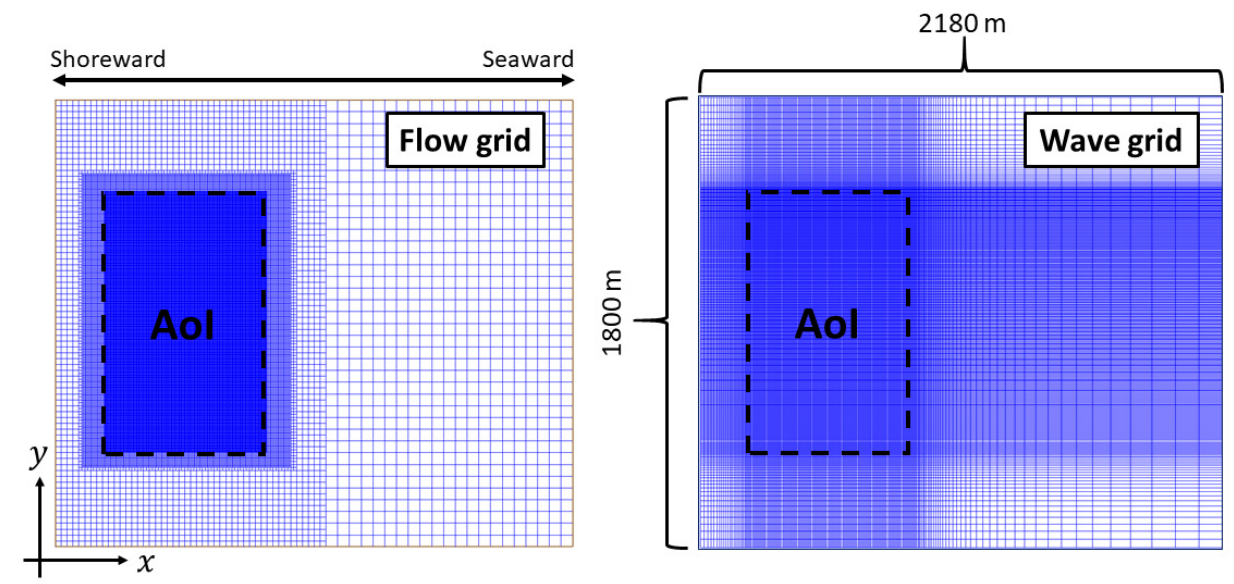

Figure 7. Computational grids used for the CMS-Flow and CMS-Wave models.

\subsubsection{Model Set up and Inputs}

The CMS-Flow model was driven with radiation stress gradients that were generated within CMS-Wave and interpolated onto its computation grid. Tides and wind stresses were neglected, and, thus, all water level displacements and currents were generated by the waves. A constant water level of zero meters was imposed on the open boundaries of the CMS-Flow model (i.e., the seaward and lateral boundaries). A moving shoreline forms the closed, landward boundary and is defined by a wetting/drying algorithm with a threshold depth of $5 \mathrm{~cm}$.

CMS-Flow's implicit solver was used with a dynamic time-step with a maximum value of $900 \mathrm{~s}$. The time-step was programmatically decreased by half if the solver did not converge within 28 iterations. The total simulation duration is 6 months, and a ramp was applied for the first hour of the simulation to smooth potential shocks.

A roller model was used to account for momentum stored in the breaking wave front before being transferred to water column, and the roller's contribution to wave mass flux was also included. A roughness coefficient, based on the local depth and a Manning's n value, was used to calculate the bottom shear stress. A spatially uniform Manning's n of 0.023 was applied. Sediment transport was calculated with the Lund-CIRP formula [39], using a single sediment fraction and a uniform grain size of $0.24 \mathrm{~mm}$. Default sediment transport parameters were used for all the simulations. Bed updating occurred with every flow/sediment transport computation time-step.

\subsection{Analysis}

Three post-processing analyses were performed on the simulation results. One computed the wave energy dissipation introduced by the nourishment. The second analyzed the longevity of the nourishment in terms of sediment retention within the placement's original footprint. The last analyzed the alongshore and cross-shore migration of the nourishment. These analyses provide a quantitative summary of two typical objectives in the design and construction of nearshore nourishments: attenuate wave energy and renourish the nearshore profile.

\subsubsection{Wave Energy Dissipation}

The analysis considered the wave energy per unit area with the AoI as well as the wave energy flux through the landward, shore-parallel control surface of the AoI (see Figure 7). Wave energy per unit area was calculated using linear wave theory as,

$$
E=\frac{1}{8} \rho g H_{m 0}^{2}
$$


where $E$ is the wave energy, $\rho$ is the density of the water $\left(1015 \mathrm{~kg} \mathrm{~m}^{-3}\right), g$ is the acceleration due to gravity, and $H_{m 0}$ is the zero-moment wave height. To analyze the effects of the nearshore nourishment, the wave energy within the AoI is normalized by the wave energy of the control case, $E^{*}$. To present the nourishment's cumulative effect, this quantity is averaged per grid cell over the first two months of the simulation, yielding

$$
\bar{E}=\frac{1}{N} \sum_{i}^{N} \frac{E_{i}}{E_{i}^{*}}
$$

where $\bar{E}$ is the mean relative wave energy change and $i$ indicates the output time-step. $\bar{E}$ varies throughout the AoI, where $\bar{E}>1$ indicates wave energy amplification and $\bar{E}<1$ indicates wave energy dissipation.

The wave energy flux per unit width (wave power) was calculated for each grid cell on the landward interface of the AoI as

$$
P=E c_{g}=\left[\frac{1}{8} \rho g H_{m 0}^{2}\right]\left[n \frac{L}{T_{p}}\right],
$$

where $P$ is the wave power, $c_{g}$ is the group velocity, $L$ is the wave length, $T_{p}$ is the peak period, and $n=\frac{1}{2}\left(1+\frac{2 k h}{\sinh 2 k h}\right)$ is the group parameter, with $k=\frac{2 \pi}{L}$ being the wave number and $h$ the local depth. The local wave length was obtained by iteratively solving the linear dispersion relation using the local depth and peak period.

The mean wave power was calculated as

$$
\bar{P}=\frac{1}{\Gamma} \int_{0}^{\Gamma} P d y,
$$

where $\Gamma$ is the length of the control surface. Finally, the relative energy dissipation introduced by the nourishment was calculated by normalizing the wave power with the nourishment by the mean wave power from the control case (i.e., without a nourishment),

$$
\bar{\alpha}=\frac{\bar{P}}{\bar{P}^{*}}
$$

where $\bar{P}^{*}$ is the mean wave power from the control case. $\bar{\alpha}$ is a function of time and varies with the offshore wave height and instantaneous morphology of the nearshore profile.

\subsubsection{Nourishment Longevity}

The question of the placed sediment's fate is an import consideration when planning nearshore nourishments. The retention of sediment within the original placement's planview template or footprint is often an objective. To assess each scenario's performance vis-à-vis this objective, the amount of sediment volume within the original footprint was tracked through time. This provides a measure of the placement's longevity under the simulated wave conditions.

The excess (deficit) volume of the nearshore nourishment relative to the control was used to assess retained sediment volume and was calculated as,

$$
V(t)=\int_{A}\left[z_{b}(t)-z_{b}^{*}(t)\right] d A,
$$

where $V(t)$ is the sediment volume within the original nearshore placement's footprint throughout the simulation, $t$ is the simulation time, $A$ is the area delineated by the original placement, $z_{b}(t)$ is the simulated bed level of the case being analyzed, and $z_{b}^{*}(t)$ is the control's bed level. The excess sediment volume was normalized by the initial excess sediment volume $\left(V_{0}\right)$ for inter-comparison. $V=1$ implies no sediment transport from the nourishment, i.e., no nourishment deflation, and $V=0$ implies total removal of the placed sediment. 


\subsubsection{Sediment Displacement}

The sediment of the initial nearshore nourishment can be transported either onshore, offshore, or in the alongshore direction. This is relevant for project design to know if potential project sites are cross-shore or longshore transport dominated. The center of mass of the nourishment is tracked through time to assess this sediment's net displacement. Conceptually, this allows the analysis of the nourishment's movement in general. If more sediment moves onshore, as opposed to offshore, then the center of mass will shift onshore. The center of mass's movement can then be analyzed in terms of cross-shore and alongshore displacement, revealing the dominant transport direction.

The coordinates for the center of mass are calculated as,

$$
(\bar{x}, \bar{y})=\left(\frac{M_{y}}{M}, \frac{M_{x}}{M}\right)
$$

where $\bar{x}$ is the cross-shore coordinate (positive onshore), $\bar{y}$ is the alongshore coordinate (positive to the left when looking at the shore from the sea), $M_{y}=\int x M d A$ is the moment about the alongshore axis, $M_{x}=\int y M d A$ is the moment about the cross-shore axis, and $M(x, y ; t)=z_{b}(x, y ; t)-z_{b}^{*}(x, y ; 0)>0$ is the accreted sediment volume over the initial equilibrium profile. Note that only positive differences are included in the calculation of volume.

\section{Results}

3.1. Waves

\subsubsection{Planform Energy Dissipation}

Surface waves undergo a number of transformations as they propagate from the continental shelf through the nearshore and eventually dissipate and/or reflect within the surfzone/swash zone. The most relevant processes for open coasts are shoaling, refraction, and wave breaking. The construction of a nearshore nourishment via external sediment sources will inevitably affect these processes. Figure 8 displays the mean relative wave energy change over the first 60 simulation days. The cases displayed are the LB, UB, and $\mathrm{DM}$ at every placement depth for the SP regional scenario.

In the LB case, it is expected that the waves will shoal and break further offshore, provided that the waves are large enough to "feel the bottom" before they reach the equilibirum profile's surfzone, i.e., where they break in the control. This is evidentally the case given the spatial distribution of $\bar{E}$ within Figure 8a-c, which shows an LB placed at depths of $3 \mathrm{~m}, 5 \mathrm{~m}$, and $7 \mathrm{~m}$, respectively. When the berm is placed at $h=3 \mathrm{~m}$, there is an increase in shoaling and, thus, wave energy seaward of the berm (located at appoximately $x=1800 \mathrm{~m}$ ). Landward of the berm, wave breaking dissipation occurs at a higher rate than in the control case leading to reduced wave energy. For the linear berms in $5 \mathrm{~m}$ and $7 \mathrm{~m}$ placement depths, minimal shoaling and breaking occur near the berms. In fact, the most obvious pattern is evident refraction-diffraction occuring landward of the berm, leading to wave energy amplification leeward of the berm.

Figure $8 \mathrm{~d}-\mathrm{f}$ shows the mean relative wave energy change for the UB at placement depths of $3 \mathrm{~m}, 5 \mathrm{~m}$, and $7 \mathrm{~m}$, respectively. The cross-shore distribution of wave energy change broadly corresponds to the LB cases, i.e., increased shoaling/breaking for the $h=3 \mathrm{~m}$ and some leeward amplification for the other placement depths. However, the undulations in the berm crest introduce an interesting alongshore pattern of wave energy amplification and dissipation. The local maxima in berm crests still caused wave breaking-induced energy dissipation, but the local minima allowed for shoaling. For the $5 \mathrm{~m}$ placement, the result is less amplification leeward of the berm, while the $7 \mathrm{~m}$ placement also shows slightly less amplification relative to the linear berm. However, the $3 \mathrm{~m}$ placement interestingly shows an increase in dissipation in the alongshore dimension at the landward interface of the AoI. The wave energy distribution introduced by the discrete mounds, shown in Figure $8 \mathrm{~g}-\mathrm{i}$, is less pronounced. The area delineated by the 
mounds' placement shows slight amplification of wave energy, but a significant dissipation relative to the control leeward of the placement is not observed.
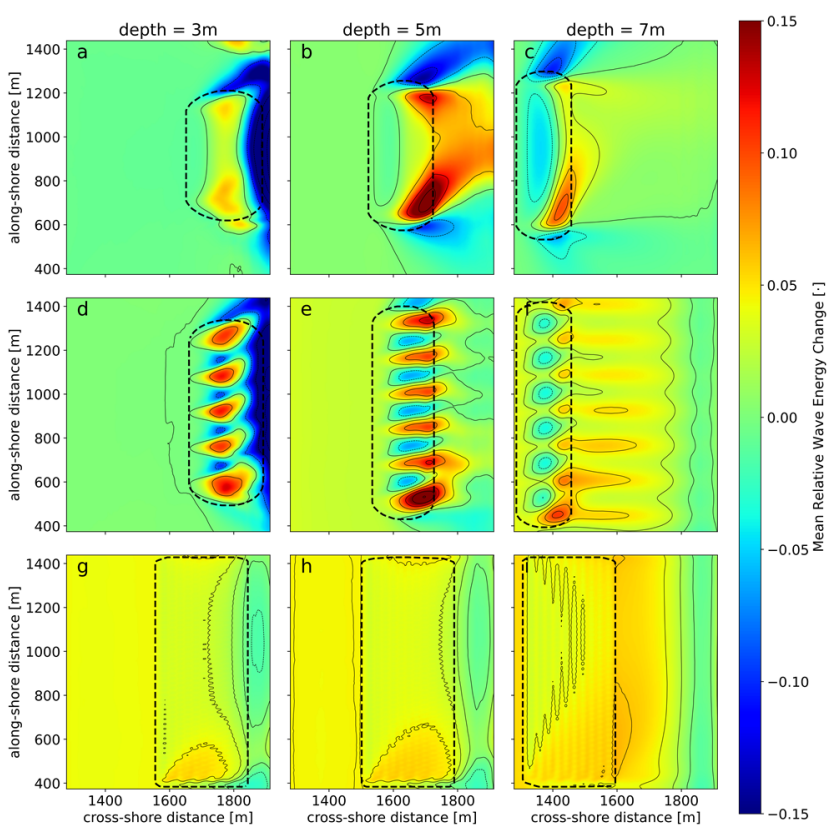

Figure 8. Mean wave energy attenuation averaged over the first two months of the South Padre Island scenario simulations. (a-c) LB at $3 \mathrm{~m}, 5 \mathrm{~m}$, and $7 \mathrm{~m}$ depths, respectively. (d-f) UB at $3 \mathrm{~m}, 5 \mathrm{~m}$, and $7 \mathrm{~m}$ depths, respectively. (g-i) DM at $3 \mathrm{~m}, 5 \mathrm{~m}$, and $7 \mathrm{~m}$ depths, respectively. Dashed black lines indicate convex hull of nourishments initial footprint.

\subsubsection{Aggregate Wave Energy Attenuation}

Effects on wave transmission are typically important for the construction of shore protection features, and this is true of nearshore nourishments. To assess wave transmission through the nearshore nourishments, mean wave power at the landward shore-parallel interface of the AoI is compared to the control as described in Section 2.3.1. Since the methods employed the simulation of a realistic time-series, as opposed to schematized wave conditions, the morphology of the nourishment evolved thoughout the simulated period. Therefore, to assess wave transmission in aggregate, the relative mean wave power $(\bar{\alpha})$ is binned according to the offshore boundary condition wave height. In this manner, trends in wave fields can be elucidated without considering individual sea-states.

Figure 9 shows relative mean wave power distributions as a function of offshore wave height for the LB, UB, and DM nourishment configuations at the SP regional scenario, respectively. In Figure 9, the relative wave power for a linear berm at $h=3 \mathrm{~m}$ shows a clear trend of reducing wave energy flux $(\bar{\alpha}<1.0)$ through the AoI compared to the placements at $5 \mathrm{~m}$ and $7 \mathrm{~m}$. The reduction in wave energy flux diminishes with smaller waves, which is expected as they are less affected by the berm. The placements at $h=5 \mathrm{~m}$ and $h=7 \mathrm{~m}$ do not appear to affect wave transmission at all as $\bar{\alpha} \approx 1.0$ for all the wave conditions, though there is slight amplification $(\bar{\alpha}>1.0)$ for the larger wave conditions. This may be due to saturation of the surfzone where the wave height at the AoI's landward interface is determined by the depth of the underlying profile at that location. 

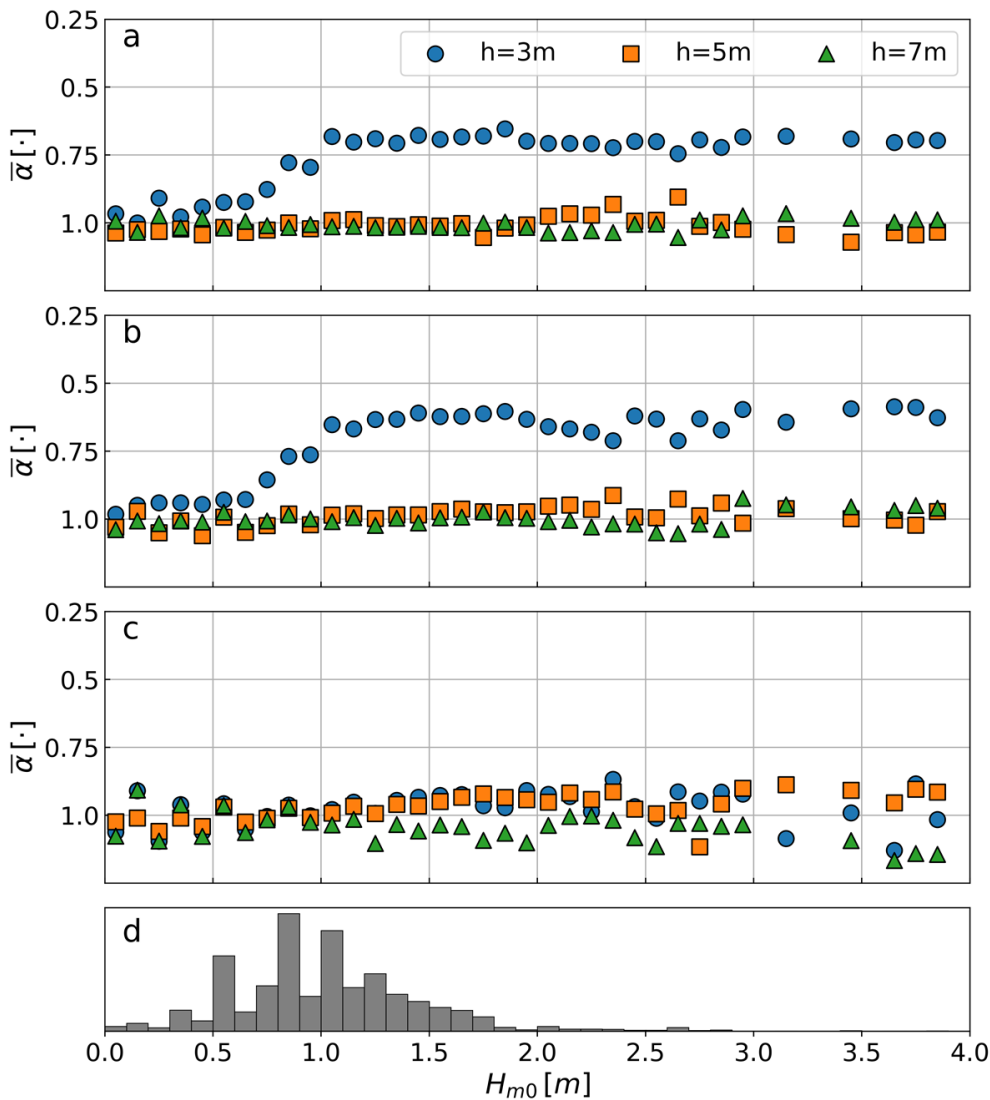

Figure 9. Relative wave power binned by offshore wave height at the South Padre Island site where the blue circles, orange squares, and green triangle markers represent the $3 \mathrm{~m}, 5 \mathrm{~m}$, and $7 \mathrm{~m}$ placement depths, respectively. (a) Linear berm; (b) undulated berm; (c) discrete mounds; (d) PDF for offshore wave height.

The trend between placement depths for the UB (see Figure $9 \mathrm{~b}$ ) is similar to the linear berm for SP. However, the magnitude of the attenuation of the mean relative wave power is appreciably greater in the UB. The LB exhibits $\bar{\alpha} \approx 0.7$ for $H_{m 0}=[1.0 \mathrm{~m}, 4.0 \mathrm{~m}]$, and the UB shows values closer to $\bar{\alpha} \approx 0.6$ for the same range of $H_{m 0}$. While it is expected that berms placed in shallower water will attenuate more wave energy than those placed deeper, it is surprising that the UB reduces wave transmission to a larger degree than the LB. Complex free-surface dynamics around the undulations may play a role here but are inaccessible in a phase-averaged model. The deeper placements show similar distributions of mean relative wave power.

The discrete mounds shown in Figure $9 \mathrm{c}$ have a less pronounced impact on wave transmission compared to the linear and undulated berms. This is expected, considering the energy attenuation results shown in Figure 8. While some of the large enhancements of wave power introduced by the DM may not be convincing and some are likely outliers (i.e., $\bar{\alpha} \approx 1.4$ in the $H_{m 0}=[3.0 \mathrm{~m}, 3.25 \mathrm{~m}]$ bin for $h=7 \mathrm{~m}$ ), there is yet a noticeable trend of increased wave power $(\bar{\alpha}>1.0)$ for the $h=7 \mathrm{~m}$ placement. This trend holds for a majority of the wave height bins, potentially indicating that the small mounds induced wave shoaling.

The trends between the LB and UB for the OD regional scenario, shown in Figure 10a, $b$, respectively, are similar to that in the SP scenario. The shallower berms $(h=3 \mathrm{~m})$ reduce wave transmission (approximately $0.8>\bar{\alpha}>0.6$ ) across all of the wave height bins, except the smallest waves $\left(H_{m 0}<0.5 \mathrm{~m}\right)$. This is compared to the deeper placements, which, for the most part, do not affect wave transmission in the LB case. All shapes and depths show an outlier for waves less than $10 \mathrm{~cm}$. The relative values shown can be particularly volatile when normalizing small values with small values. These small waves have a negligible 
effect on the nourishment morphology, but are shown for completeness. In the UB case, there is a notable amplification in wave transmission for waves with a wave height between $1 \mathrm{~m}$ and $0.5 \mathrm{~m}$ for the $7 \mathrm{~m}$ placement depth. Further, the trend between placement depths for the DM in the OD scenario, see Figure 10c, is also similar to that in the SP scenario (Figure 9c). The deepest placement $(h=7 \mathrm{~m})$ exhibits some wave amplification for all the wave height bins $(1.2>\bar{\alpha}>1.0)$, while the shallower placements have little effect on wave transmission.
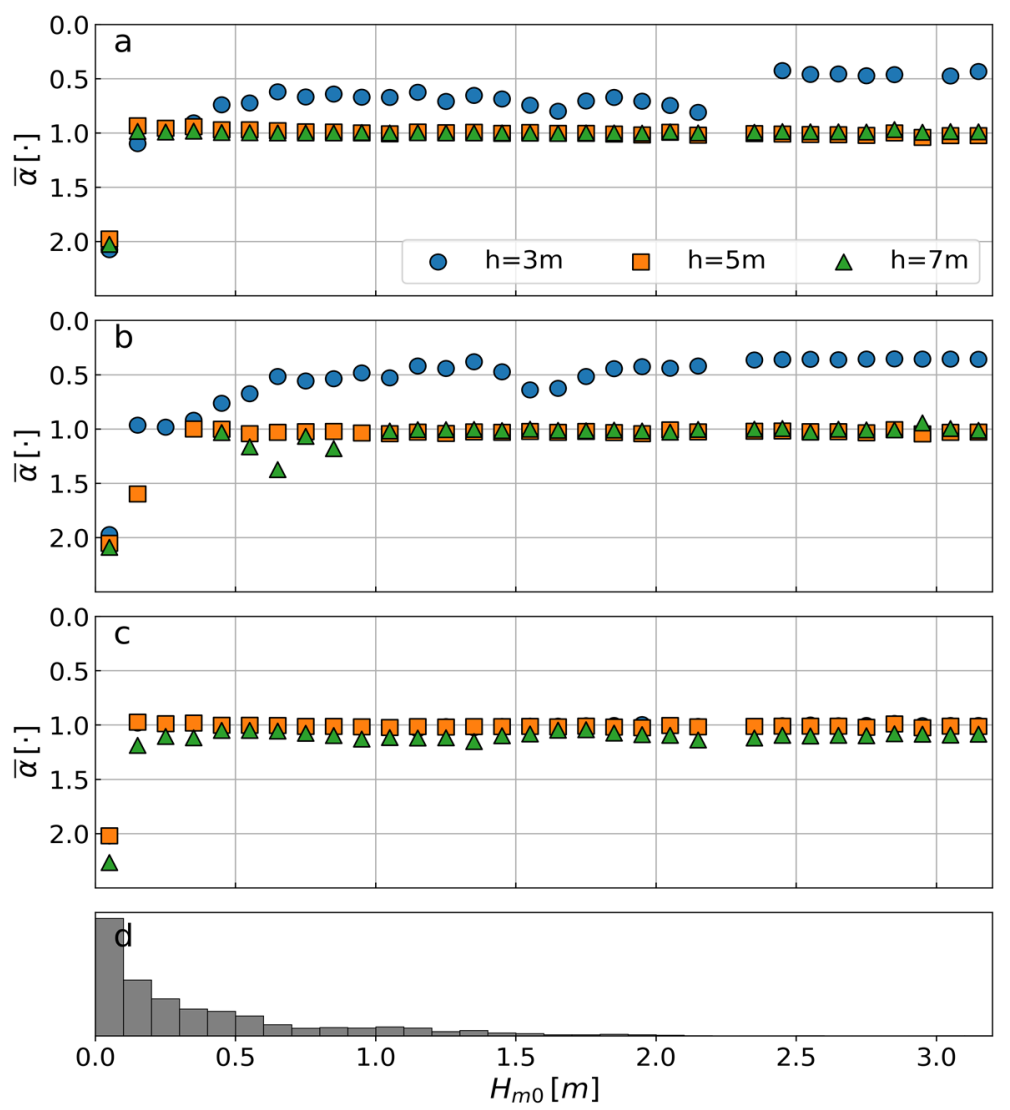

Figure 10. Relative integrated wave power binned by offshore wave height for the Ogden Dunes regional scenario where the blue circles, orange squares, and green triangle markers represent the $3 \mathrm{~m}, 5 \mathrm{~m}$, and $7 \mathrm{~m}$ placement depths, respectively. (a) Linear berm; (b) undulated berm; (c) discrete mounds; (d) probability density function for offshore wave height.

The aggregate effects of the $\mathrm{LB}, \mathrm{UB}$, and $\mathrm{DM}$ on wave transmission for the VB regional scenario are presented in Figure 11. The general trends in the VB scenario differ from the SP and OD scenarios. Specifically, the UB does not clearly show more wave energy attenuation than the LB, as opposed to the SP and OD scenarios. Further, the difference in attenuation between the $3 \mathrm{~m}$ and $5 \mathrm{~m}$ placements at $\mathrm{VB}$ is not as pronounced as the other sites, which is potentially due to the longer period waves at VB. For both the LB and UB cases, the deepest placement $(h=7 \mathrm{~m})$ leads to some wave energy amplification in medium wave heights $\left(0.5 \mathrm{~m}<H_{m 0}<1.75 \mathrm{~m}\right)$. Also, for the LB, smaller waves $\left(H_{m 0}<0.75 \mathrm{~m}\right)$ in the deepest placement depth are attenuated more than with the shallower placements, but attenuation for these wave bins is similar between placement depths for the UB. 

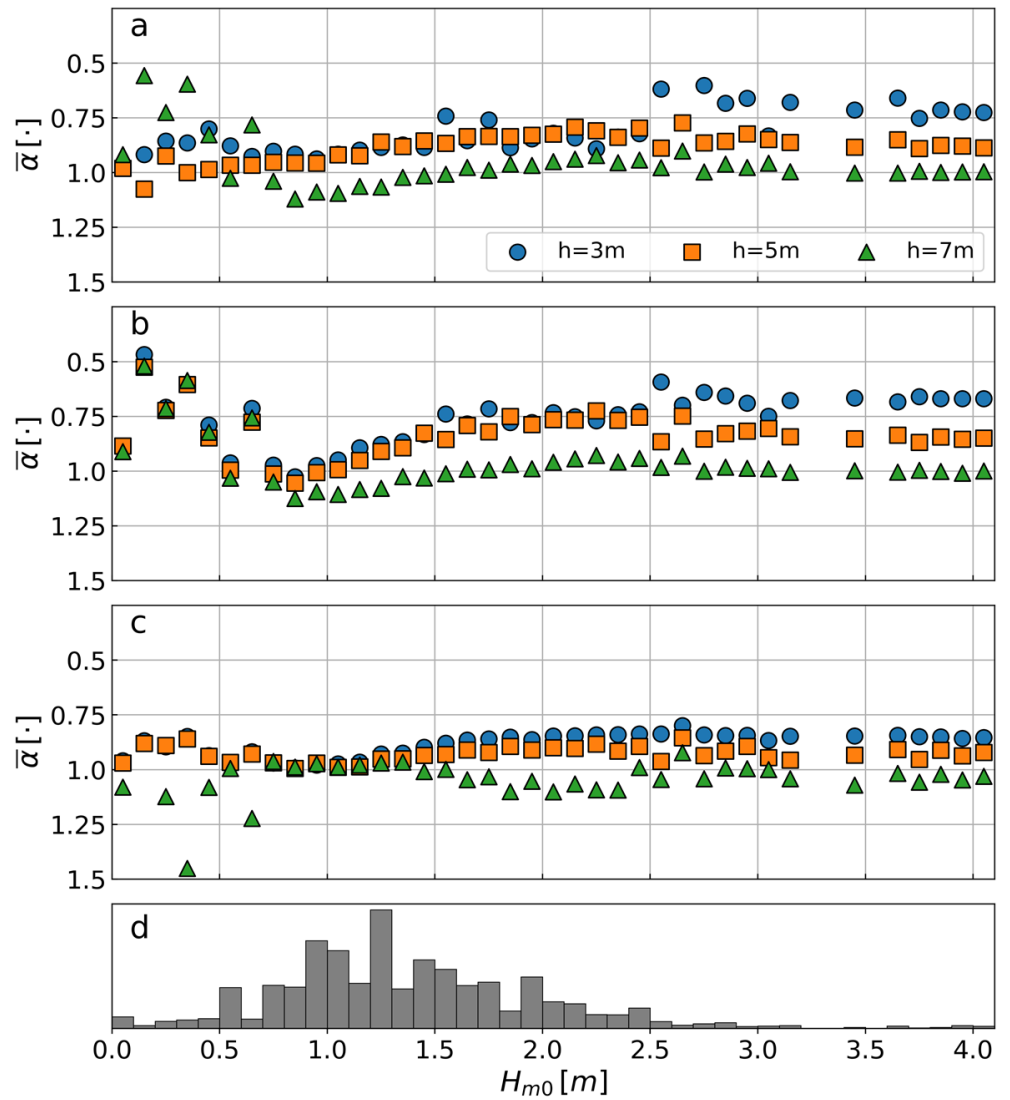

Figure 11. Relative integrated wave power binned by offshore wave height for Vilano Beach where the blue circles, orange squares, and green triangle markers represent the $3 \mathrm{~m}, 5 \mathrm{~m}$, and $7 \mathrm{~m}$ placement depths, respectively. (a) Linear berm; (b) undulated berm; (c) discrete mounds; (d) probability density function for offshore wave height.

The wave height distributions (see panel $d$ in Figures 9-11) indicate that the largest waves, which typically exhibit the highest energy attenuation value, are infrequent compared to the median wave height. However, both the infrequent, high-energy events and the more typical sea-states are attenuated to a greater degree by the shallower placements. The exception to this is the OD scenario, which follows a different wave height distribution that resembles the Gamma distribution, whereas the SP and VB scenarios more closely approximate a Rayleigh distribution. The OD site is located on the southern tip of Lake Michigan and is influenced by different wave generation mechanisms. The most frequent OD waves are less than $10 \mathrm{~cm}$ and show amplification under each nourishment shape and placement depth.

The LB and UB, when placed shallow enough, potentially attenuate $20 \%$ to $60 \%$ of the wave energy on average for wave heights larger than $0.5 \mathrm{~m}$. On the other hand, the $\mathrm{DM}$ at any depth typically do not attenuate wave energy and, in some cases, cause wave amplification. This result is expected as the smaller height of the discrete mounds compared to the shore-parallel berms, due to distributing an equal amount of sediment over a larger extent, does not generate wave-breaking induced energy dissipation to the same degree. Presumably, the DM act to decrease the nearshore profile's depth over a larger distance, but not significant depth-limited breaking, and induce some shoaling that is not present in the control case leading to minor wave energy amplification. 


\subsection{Sediment Transport/Morphology Change}

\subsubsection{Nourishment Longevity}

Nearshore nourishment projects are often constructed to nourish the beach profile for an intended period of time. Some are intended to deflate quickly to nourish adjacent beaches, and others are intended to retain sediment in the original placement for extended periods of time [5,40]. This is assessed here by tracking the excess (or deficit) sediment volume within the placement's footprint. Figures 12-14 show a time series of the percent volume retained through time, as well as the wave forcing, for the SP, OD, and VB regional scenarios, respectively.
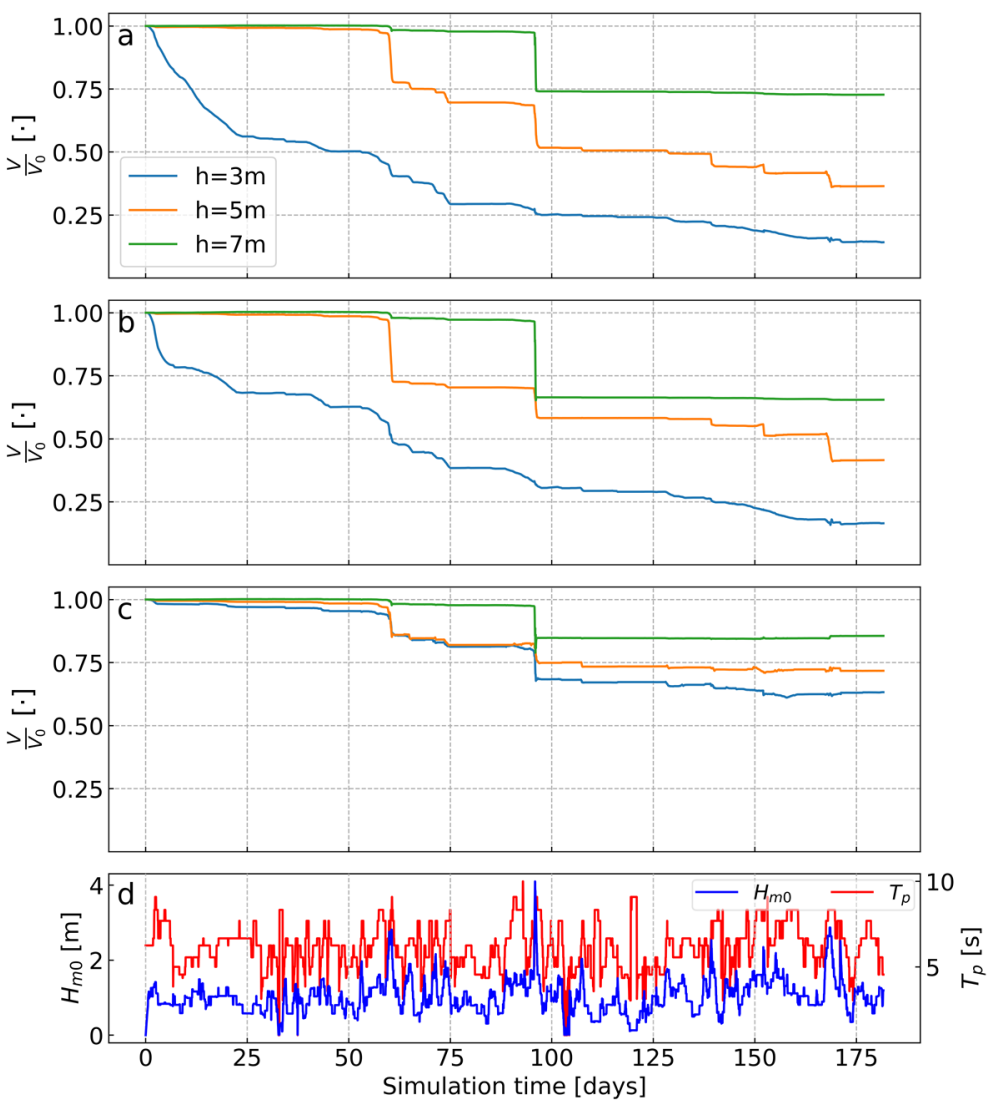

Figure 12. Longevity of nearshore nourishments at South Padre Island site in terms of percent placed volume remaining in original footprint through time where the blue, orange, and green colors represent the $3 \mathrm{~m}, 5 \mathrm{~m}$, and $7 \mathrm{~m}$ placement depths, respectively. (a) Linear berm; (b) undulated berm; (c) discrete mounds; (d) time series of offshore zero-moment wave height and peak period.

The SP longevity curves (Figure 12) are clearly marked by episodic events, especially for the deeper placements $(h=5 \mathrm{~m}$ or $h=7 \mathrm{~m}$ ). This is likely due to the limited potential of the smaller waves for sediment remobilization at the greater depths. The LB and, to a slightly lesser extent, the UB exhibit continuous sediment transport away from the original placement footprint for the shallowest placement $(h=3 \mathrm{~m})$. The rate of nourishment deflation, i.e., reduction of placed sediment volume, for this placement depth appears approximately exponential for the LB, while the UB appears more linear after an initial adjustment. The DM placement at all depths more or less only responds to the two large events at approximately 60 and 95 days. Outside these two events, there is small, continuous deflation for the shallowest placement only. 

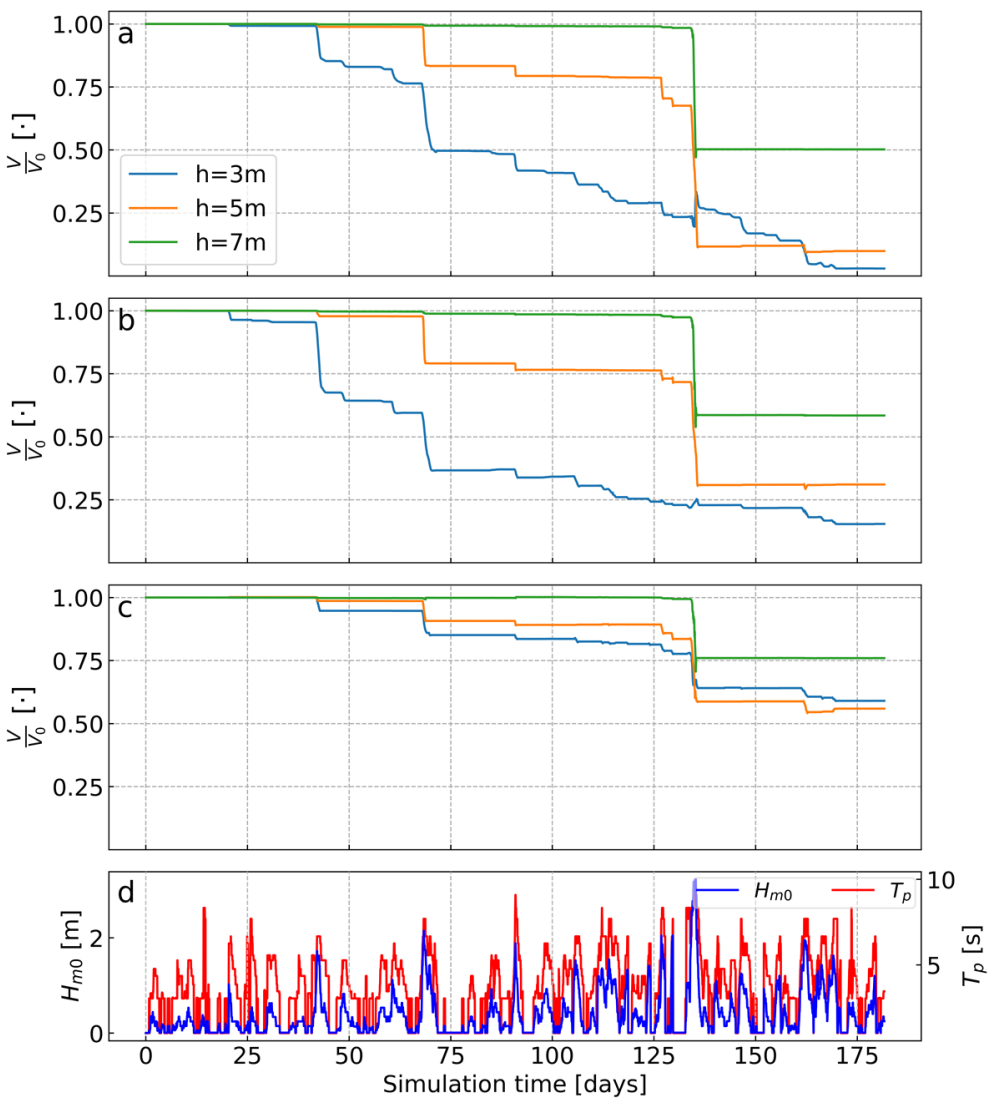

Figure 13. Longevity of nearshore nourishments at the Ogden Dunes site in terms of percent placed volume remaining in original footprint through time where the blue, orange, and green colors represent the $3 \mathrm{~m}, 5 \mathrm{~m}$, and $7 \mathrm{~m}$ placement depths, respectively. (a) Linear berm; (b) undulated berm; (c) discrete mounds; (d) time series of offshore zero-moment wave height and peak period.

The longevity curves for the OD regional scenario appear more episodic than the SP curves, especially for the LB and UB placements at $h=3 \mathrm{~m}$. As opposed to the SP scenario, there is little continuous nourishment deflation outside the events. The morphodynamics of the DM are also episodic. It is interesting that only one event (at approximately day 130) remobilized the deepest placement $(h=7 \mathrm{~m})$, but it does so to a large degree, deflating almost $50 \%, 45 \%$, and $25 \%$ of the sediment volume for the LB, UB, and DM placement shapes, respectively. This is also exhibited by the SP scenario for the large event at approximately day 95, except the relative quantity of berm deflation was not as large. These energetic events also deflate the deeper placements to a larger degree relative to the shallower placements. This suggest that large events are required to mobilize sediments placed deeper in the water column, as would be expected, and that, as they are more frequently reworked by waves, the shallower placements are more likely to be closer to equilibrium when large events occur.

The nourishment longevity at the energetic VB site (Figure 14) has some notably different features from the other two locations, but is comparable to the trends observed at SP. The LB and UB exhibit an initial period of adjustment at $h=3 \mathrm{~m}$, followed by gradual evolution, similar to SP, while the deeper placements are markedly episodic. The longevity of the DMs at VB also shares characteristics with the other regional scenarios. The deepest placement is mostly unaffected by anything besides the largest high-energy events. The longevity of $h=3 \mathrm{~m}$ and $h=5 \mathrm{~m}$ placements track each other through time, but the shallower placement responds to forcing to a large degree, leading to a systematic difference. It should be noted that the 2015 nearshore berm constructed at VB in approximately $3 \mathrm{~m}$ became significantly deflated within 60 days and completely dispersed within 120 days [28], qualitatively replicating the current study's idealized results. 

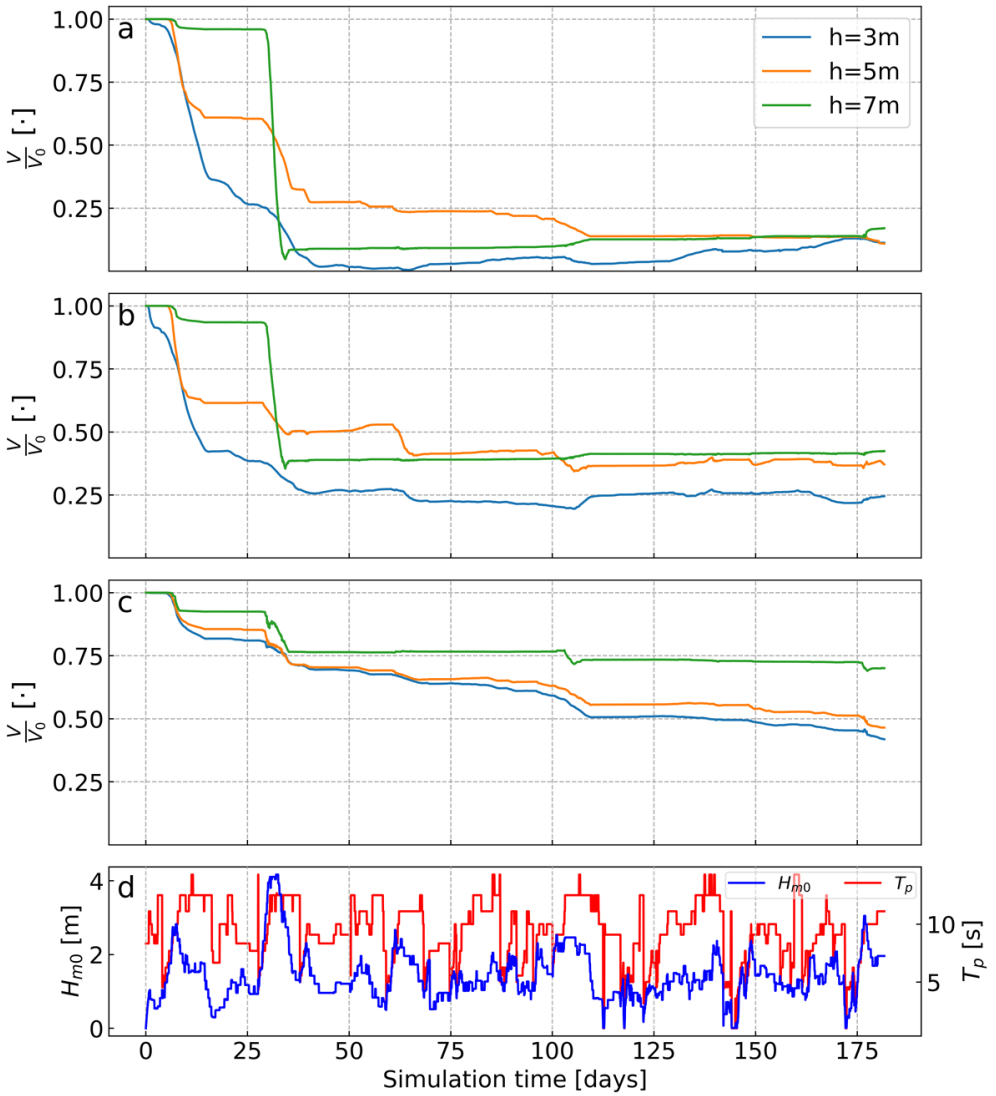

Figure 14. Longevity of nearshore nourishments at Vilano Beach site, in terms of percent placed volume remaining in original footprint through time where the blue, orange, and green colors represent the $3 \mathrm{~m}, 5 \mathrm{~m}$, and $7 \mathrm{~m}$ placement depths, respectively. (a) Linear berm; (b) undulated berm; (c) discrete mounds; (d) time series of offshore zero-moment wave height and peak period.

A prolonged, high-energy event between day 5 and 18 significantly displaced sediment from the $3 \mathrm{~m}$ and $5 \mathrm{~m}$ LB and UB placements, but it did not mobilize sediment from the deeper placement. Significant deflation for the $h=7 \mathrm{~m}$ placement occurred approximately 10 days later (peak wave height at simulation day 30 ) where nearly $80 \%$ and $50 \%$ of the LB and UB berms sediment was transported away from the AoI, respectively. After this highenergy event, there is minor berm deflation for the LB or UB at any placement depth, in spite of additional high-energy events, suggesting that the profile has sufficiently adjusted towards equilibrium. The DMs' sediment volume at VB respond to the same events, but the deflation was reduced.

\subsubsection{Cross-Shore/Alongshore Displacement}

Nourishment deflation quantifies volumetric change rate and implies sediment transport away from the placement site, but does not elucidate the sediment's kinematics, which are important for design and management. Whether a nourishment migrates onshore, offshore, or alongshore figures substantially in the nearshore sediment budget and will influence shoreline morphodynamics. The evolution of cross-shore profiles is presented in Figures 15-17. The cross-shore profile is located in the middle of the domain. The shallow LB typically migrate onshore, while deeper placements show deflation of the nourishment, at least at the center profile. The shallow UB migrate on shore as well, but show more deflation than the LB. The DM appear to smooth out and contribute to the nearshore profile's elevation over a larger extent. 


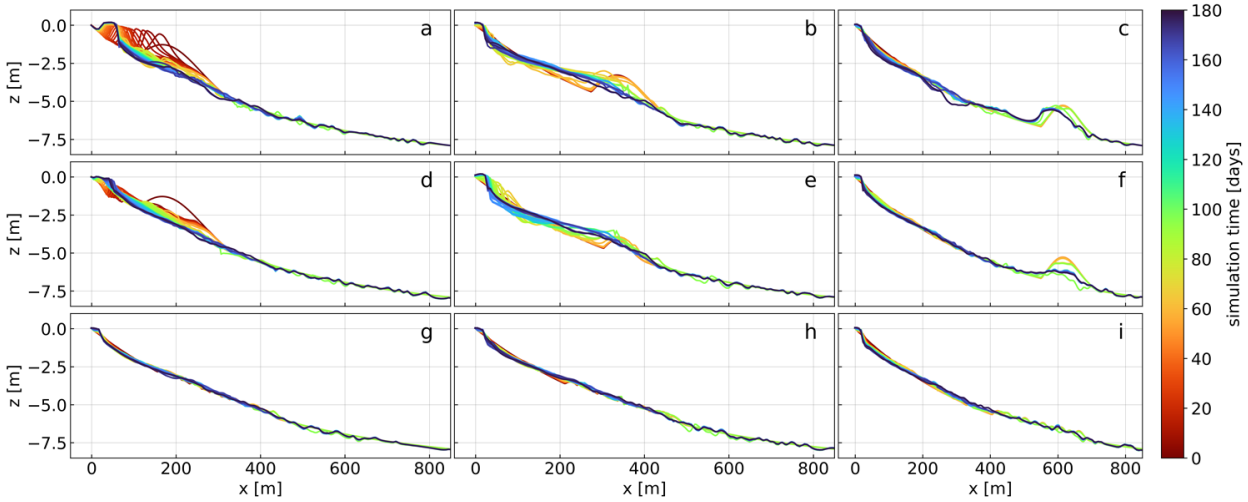

Figure 15. Central profile evolution for SP, where color indicates elapsed simulation time. (a-c) LB at $3 \mathrm{~m}, 5 \mathrm{~m}$, and $7 \mathrm{~m}$ depths, respectively. (d-f) UB at $3 \mathrm{~m}, 5 \mathrm{~m}$, and $7 \mathrm{~m}$ depths, respectively. (g-i) DM at $3 \mathrm{~m}, 5 \mathrm{~m}$, and $7 \mathrm{~m}$ depths, respectively.

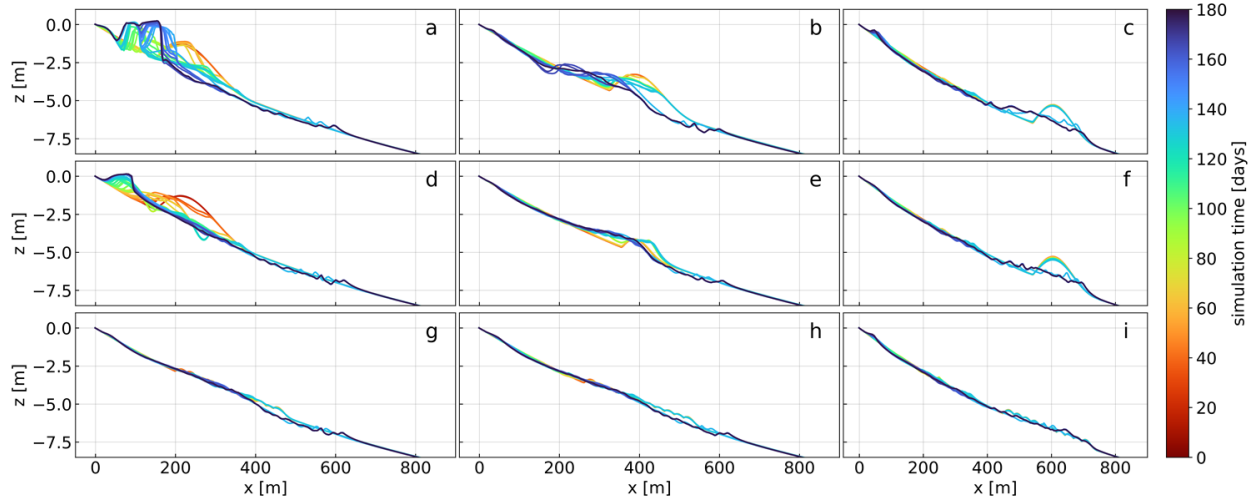

Figure 16. Central profile evolution for OD, where color indicates elapsed simulation time. (a-c) LB at $3 \mathrm{~m}, 5 \mathrm{~m}$, and $7 \mathrm{~m}$ depths, respectively. (d-f) UB at $3 \mathrm{~m}, 5 \mathrm{~m}$, and $7 \mathrm{~m}$ depths, respectively. (g-i) DM at $3 \mathrm{~m}, 5 \mathrm{~m}$, and $7 \mathrm{~m}$ depths, respectively.

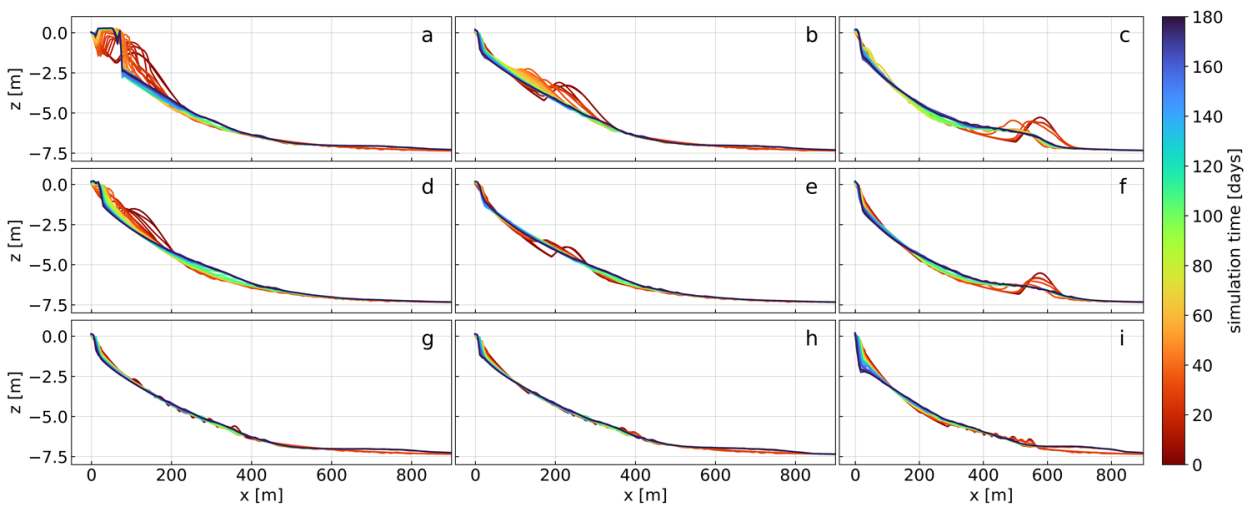

Figure 17. Central profile evolution for VB, where color indicates elapsed simulation time. (a-c) LB at $3 \mathrm{~m}, 5 \mathrm{~m}$, and $7 \mathrm{~m}$ depths, respectively. (d-f) UB at $3 \mathrm{~m}, 5 \mathrm{~m}$, and $7 \mathrm{~m}$ depths, respectively. (g-i) DM at $3 \mathrm{~m}, 5 \mathrm{~m}$, and $7 \mathrm{~m}$ depths, respectively.

To better understand the sediment's bulk movement, the nourishment's center of mass is calculated through time and expressed as the cross-shore and alongshore displacements from its original position. Figures 18-20 show the different nourishment centers of mass for the SP, OD, and VB scenarios, respectively. The nourishment migration for the SP scenario in Figure 18 shows that there is considerable difference between the morphodynamics of the LB and UB placement types. While it was expected that the DM would display 
characteristics largely different from the other two nourishment types, the similarity between the LB and UB morphologies (alongshore linear features) was expected to lead to similar cross-shore/alongshore movement. This is clearly not the case, as the shallower placements $(h=3 \mathrm{~m}$ and $h=5 \mathrm{~m}$ ) for the LB show large alongshore displacements, while the same placement depths for the UB do not. The cross-shore displacements for each nourishment shape are similar in character. There is either onshore migration or minimal movement outside high-energy events that transport sediment offshore. The tendency to migrate onshore seems to increase with increasing placement depth.

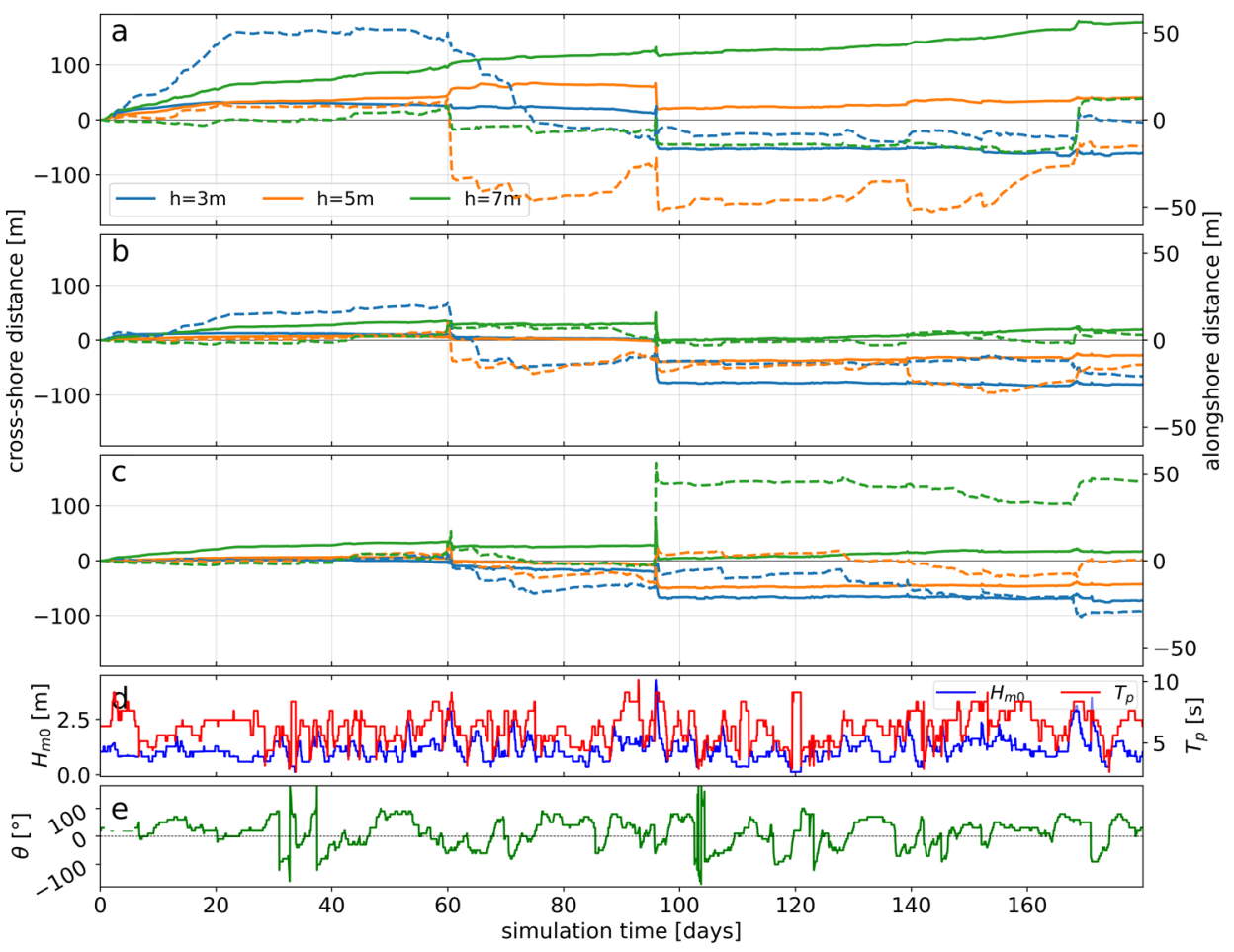

Figure 18. Time series of cross-shore (solid line) and alongshore (dashed lines) displacements of nearshore nourishment sediment for the South Padre Island scenario for $3 \mathrm{~m}$ (blue lines), $5 \mathrm{~m}$ (orange lines), and $7 \mathrm{~m}$ (green) placement depths, respectively. (a) Linear berm; (b) undulated berm; (c) discrete mounds; (d) offshore wave height and peak period; (e) wave direction relative to shore-normal.

The characteristic of nourishment migration at OD (Figure 19) shows similarity between the LB and UB, and to a lesser degree the DM, in contrast to the dissimilarity in the SP scenario. For the LB, UB, and DM, there is strict onshore movement with minimal offshore transport during high-energy events, which increases for the deeper placements ( $h=5 \mathrm{~m}$ and $h=7 \mathrm{~m}$ ). The alongshore movement increases with decreasing depth and is in the same direction for each nourishment shape and placement depth. Further, the patterns of cross-shore and alongshore movement for the $3 \mathrm{~m}$ placement depth, and to a lesser extent the $5 \mathrm{~m}$ and $7 \mathrm{~m}$ placements, is nearly identical between the LB and UB shapes.

Nearshore nourishment migration at the VB scenario (Figure 20) is distinctly marked by the high-energy event around day 30 . For the LB, at the $h=3 \mathrm{~m}$ depth, the nearshore berm is displaced offshore more than $100 \mathrm{~m}$ in the course of a day. The pattern is the same for the $h=5 \mathrm{~m}$ placement but is reduced in magnitude, but the deepest placement migrates onshore during this event. These trends for the UB are different in that the event does not force offshore movement for the $h=3 \mathrm{~m}$ or $h=5 \mathrm{~m}$ placements but does generate some onshore migration for the $7 \mathrm{~m}$ placement. The dissimilarity between the UB and LB shapes at VB accords with the SP scenario, but contrasts with the conformity of responses found at the OD site. 


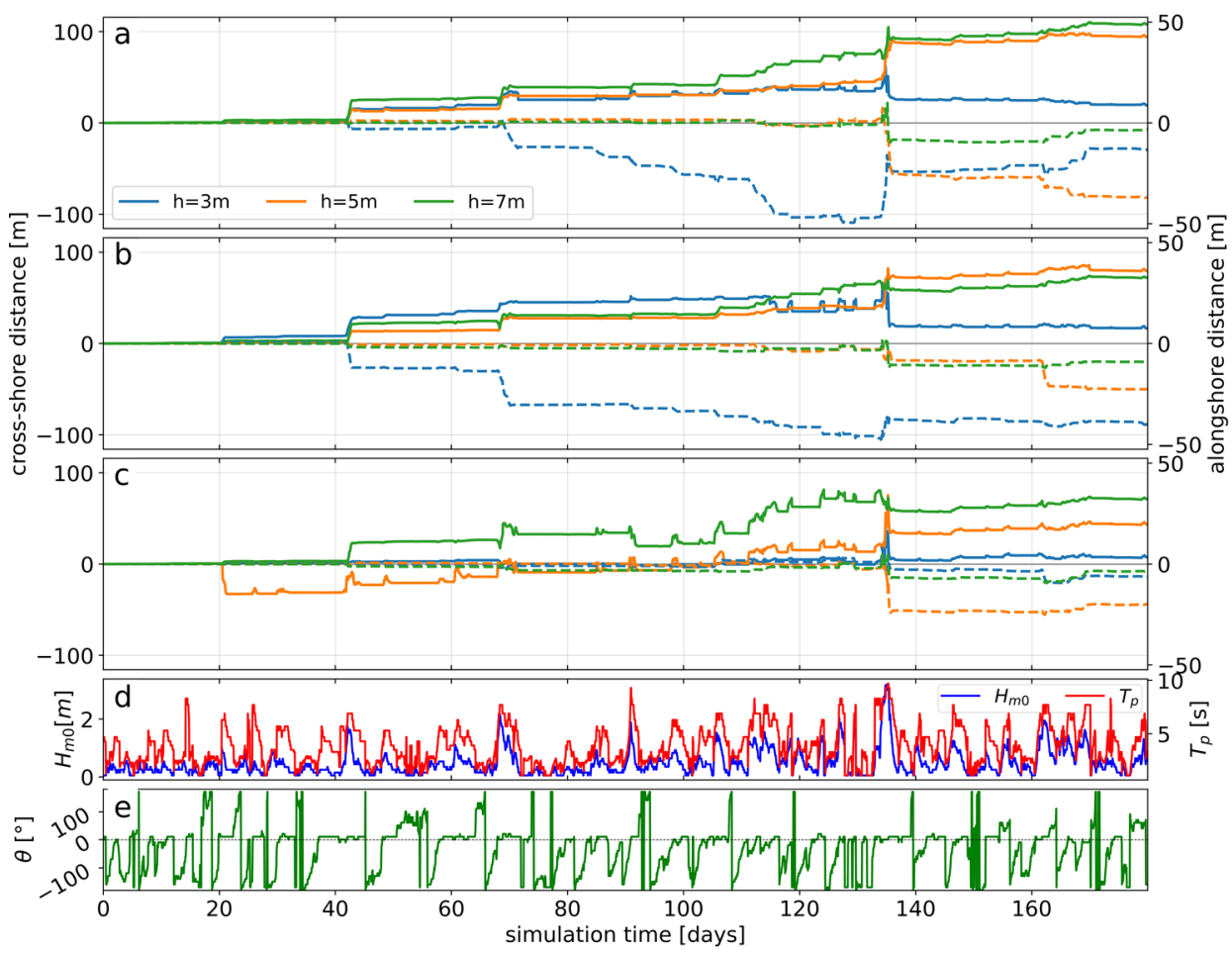

Figure 19. Time series of cross-shore (solid line) and alongshore (dashed lines) displacements of nearshore nourishment sediment for the Ogden Dunes scenario for $3 \mathrm{~m}$ (blue lines), $5 \mathrm{~m}$ (orange lines), and $7 \mathrm{~m}$ (green) placement depths, respectively. (a) Linear berm; (b) undulated berm; (c) discrete mounds; (d) offshore wave height and peak period; (e) wave direction relative to shore-normal.

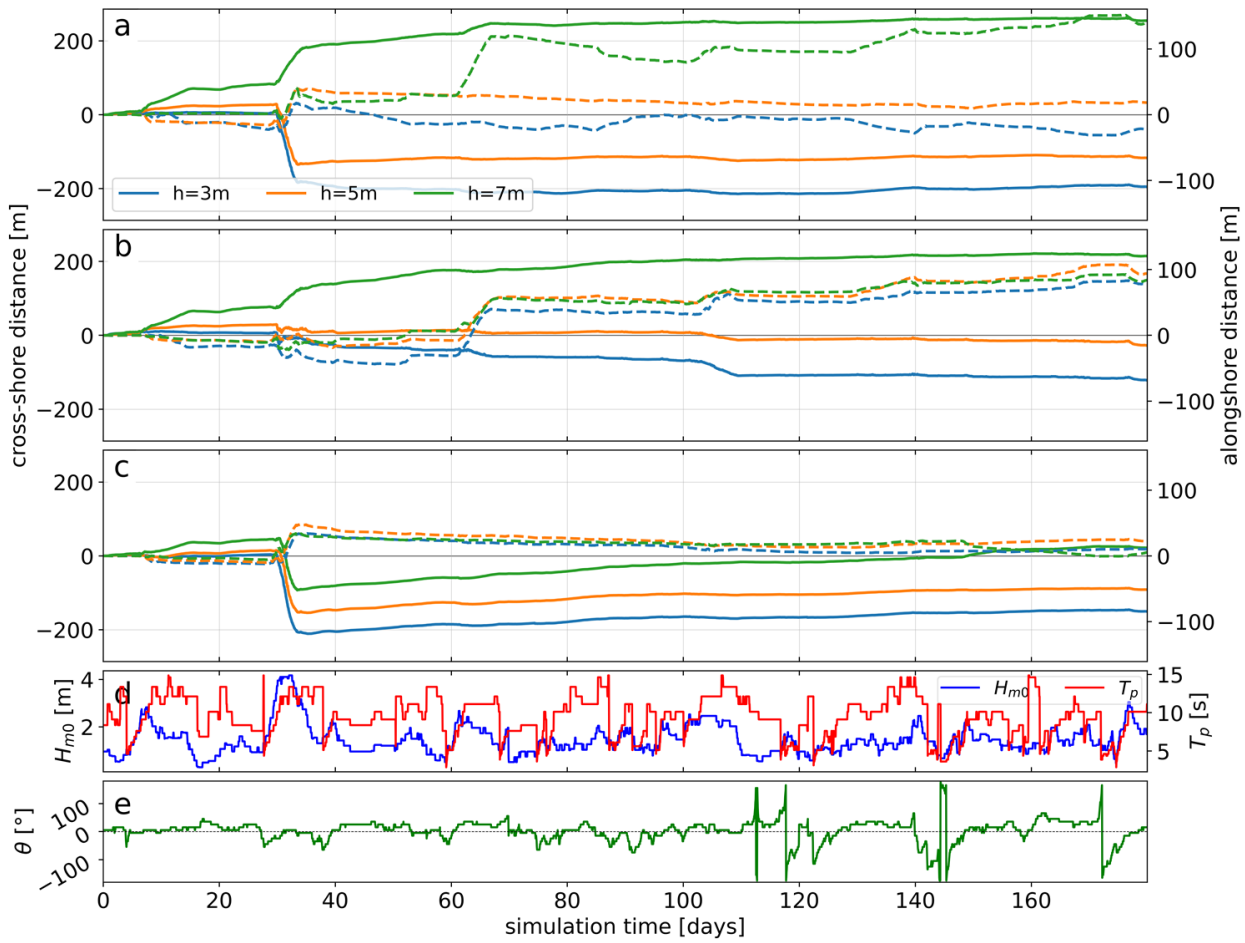

Figure 20. Time series of cross-shore (solid line) and alongshore (dashed lines) displacements of nearshore nourishment sediment for the Vilano Beach scenario for $3 \mathrm{~m}$ (blue lines), $5 \mathrm{~m}$ (orange lines), and $7 \mathrm{~m}$ (green) placement depths, respectively. (a) Linear berm; (b) undulated berm; (c) discrete mounds; (d) offshore wave height and peak period; (e) wave direction relative to shore-normal. 
The DM are similarly displaced offshore by the high-energy event at day 30, except that the $h=7 \mathrm{~m}$ placement also moves offshore whereas the LB and UB migrate onshore. In each nourishment shape, there is initially negative alongshore displacement, followed by alongshore migration in the opposite direction after the same event. After that point, the alongshore patterns diverge, but the general trend is slow migration in the negative direction.

In general, the $h=7 \mathrm{~m}$ placements migrate onshore over the simulation period. The DM in the VB scenario appear to be an exception to this, but, in spite of the episodic offshore movement near day 35, the net displacement of the nearshore nourishment is onshore. The shallower placements $(h=3 \mathrm{~m}$ or $h=5 \mathrm{~m}$ ) show considerably more variability between regions and nourishment shapes, outside the episodic nature of sediment transport. The net direction, i.e., onshore/offshore and \pm alongshore, are typically the same for the LB and UB at a given region with comparable magnitudes of displacement. It is also noted that, although the OD nourishments deflate slowly, implying mild sediment transport rates, the direction of transport was dominantly onshore.

\section{Discussion}

In general, the results indicate several trends, including (1) shallower placements attenuate more wave energy; (2) shallower placements tend to evolve more continuously due to enhanced wave-driven sediment transport; (3) nearshore nourishment transport is typically onshore outside of periodic high-energy events, which generate offshore sediment transport.

\subsection{Wave Attenuation}

\subsubsection{The Influence of Placement Depth}

The clearest observable trend is that shallow placement depths are critical to appreciable wave energy attenuation. The central interquartile range of waves at the SP and VB regional scenarios exhibit greater mean wave energy attenuation for the shallower placements, thus indicating that appreciable energy attenuation is occurring for the majority of the waves. Consequently, both the infrequent, high-energy events and the more typical sea-states are attenuated to a greater degree by the shallower placements. Nearshore nourishments often produce shoreline morphodynamics, i.e., a landward salient, similar to submerged breakwaters [28]. The wave attenuation landward of the nourishments suggest that alongshore gradients in the alongshore component of the radiation stress generates convergent alongshore currents and, thus, accretion.

The amplified smaller waves at OD likely break near the shoreline and are not significantly influenced by the nearshore nourishment. Additionally, the large relative amplification for these small waves only indicates an increase of a few centimeters, which is within the range of numerical modeling accuracy. These smaller waves may play a marginal role in shoreline morphodynamics and wave heights $>0.3 \mathrm{~m}$ at this site, following the observable trend of increased wave energy attenuation with shallower placement. The observation that placement depth may produce wave amplification within the AoI is clearly the case for the DM at the SP and VB regional scenarios. When placed at $h=7 \mathrm{~m}$ there is nontrivial $(\bar{\alpha}>10 \%)$ amplification for the larger wave heights. While this also occurs for the shallower placements, the trend is not as general. The causal mechanism is not clear, but it may be generated by refraction into the control interface of the AoI caused by the shallower placement area. This wave transformation process is evident in Figure 8, and the free-surface dynamics of AoI may be a future topic of investigation.

In practice, the placement depth should depend on the wave climate and be determined during the design phase of the nearshore nourishment strategy. For instance, only the $h=3 \mathrm{~m}$ placement attenuates wave energy for the SP and OD scenarios (see panel a and $b$, Figures 9 and 10, respectively), while there is comparable energy attenuation between the $h=3 \mathrm{~m}$ and $h=5 \mathrm{~m}$ placements for many wave height bins in the VB scenario (see panel a and b in Figure 11). In consideration of the longevity curves in Figures 12-14, 
where the deeper berms' deflation is driven by high-energy, episodic events, one could argue for a sophisticated approach to design where wave energy attenuation is optimized for a certain range of wave height, while longevity is optimized by placing the berm deep enough to avoid continuous evolution. This may be a zero-sum game, in that attenuating wave energy is a driver of berm deflation. However, the mechanisms of sediment transport (e.g., wave-averaged transport versus wave-breaking induced alongshore current transport) would vary depending on placement depth and influence berm deflation rates. Future in-depth analysis of the relevant sediment transport mechanisms may include phase resolving wave models.

\subsubsection{The Influence of Nourishment Shape}

A clear distinction between the alongshore bar-type berms, i.e., the linear and undulated berms, and the discrete mounds is evident in the wave attenuation results. While placement depth is critical for inducing wave-breaking energy dissipation, nourishment shape largely determines if wave energy attenuation occurs. For the SP and OD scenarios, appreciable wave attenuation only occurs for the LB and UB. The VB scenario is the exception, in that the DM attenuate wave energy at the $3 \mathrm{~m}$ and $5 \mathrm{~m}$ depths for the larger waves, however the most frequent waves do not exhibit much attenuation. Clearly, if shoreline protection through wave energy attenuation is a design objective, then mimicking an alongshore bar during berm construction should be pursued.

Comparing the influence of nourishment shape between the LB and UB wave attenuation analyses reveals an unexpected result. The UB clearly attenuates more wave energy at the higher wave heights and, to a lesser degree, at the middle wave heights. This is somewhat counterintuitive in that the undulations would presumably not generate as uniform wave-breaking energy dissipation within the incident wave field. Further, this is evidenced by the spatial distribution of mean relative wave energy in Figure 8. However, the UB clearly affects wave transmission through the AoI to a larger degree than the LB, particularly in the SP and OD scenarios. A plausible explanation is the difference in alongshore length between the LB and UB. The undulations in berm crest height in the UB necessitated an extension in the berm's alongshore dimension to maintain an approximately constant nearshore nourishment volume between placements. This is a positive result, considering most linear nearshore berm projects are constructed with undulations due to construction techniques such as periodic movement of the sediment discharge pipe [36]. Differences in the longevity of the $3 \mathrm{~m} \mathrm{UB}$ and LB may also contribute to the different wave attenuation results. The shallow UB disperse at somewhat slower rates in the SP and VB cases, so there may have been a larger fraction of the berm impacting some of the waves for a longer duration.

This trend has important implications for nearshore nourishment design. If undulated berms consistently attenuate wave transmission to a larger degree, and do so by sheltering a larger stretch of shoreline, then berm design should optimize alongshore extent. The optimization needs to consider the undulation's maximum berm crest height required to induce wave breaking, as well as the alongshore wave length required to dissipate sufficient energy. Further numerical modeling may be able to explore a parameter space of undulated berm designs with the aim to investigate whether any easily constructible undulation dimensions clearly optimize wave energy dissipation.

\subsection{Sediment Transport and Nourishment Migration}

\subsubsection{Nourishment Deflation Rates}

The design lifespan of nearshore nourishments depends on the rate at which sediment is exported from the initial placement and, therefore, the rate at which the nourishment's volume decreases, i.e., the nourishment deflation rate. The deflation rate is a function of sediment transport that depends on the nearshore hydrodynamics and sedimentology. Here, we have controlled for these factors to explore the effects of nourishment shape and the cross-shore/alongshore distribution of nearshore nourishment material. 
One evident trend in the longevity curves (see Figures 12-14) is the difference between episodic events and continuous background evolution. The DM do not exhibit appreciable background sediment transport and are instead dominated by episodic sediment transport. The longevity curves are punctuated by step-wise deflation corresponding to the highenergy events, where the wave height was large enough to mobilize the sediment. The movement of the DMs' centers of mass were similar between placement depths with generally the same alongshore/cross-shore trajectories per regional scenario. The deeper placements $(h=7 \mathrm{~m})$ for LB and UB show a similar pattern and are only remobilized by the largest events within the simulations. Interestingly, the UB placements generally deflate less than the LB for the same events, e.g., for the event at day 130 at the SP scenario, the LB lost approximately 50\% of volume while the UB lost approximately $40 \%$. These results suggest that if retaining sediment on the profile is the primary objective, then deeper, more diffuse placements may optimize nourishment longevity.

\subsubsection{Direction of Net Sediment Transport}

In general, the direction of net sediment transport and the relative importance of the episodic deflation varies with nourishment shape and placement depth. However, the center of mass trajectories (see Figures 18-20) show that sediment is often transported onshore, especially for the deepest placements. During the high-energy storm events, a large amount of sediment is then transported offshore with a return to onshore transport that is inconsistent between nourishment types and placement depths. This result has been observed in other nearshore nourishment laboratory studies [13] and is expected, as it has long been recognized that storm events tend to move beach/beachface sediment offshore to form an offshore bar.

A few of the simulations exhibit net seaward transport, which is contrary to the expected behavior of onshore movement for nearshore nourishments [9]. However, this may be due to the number of storm events and the length of the simulation. Given the positive trend in the centroids' cross-shore position through time, it is reasonable to assume that net onshore movement would result after a longer duration. The steady onshore movement of some placements (e.g., the LB placed at $3 \mathrm{~m}$ at Vilano Beach in Figure 20a) outside the events suggests that the profiles are out of equilibrium with the wave climate or the bed's sediment composition, which would prefer to generate a steeper profile. This concept could be useful for the practice of beneficially placing nearshore nourishments. For example, if the antecedent conditions of the nearshore profile are out of equilibrium, then sediment could be placed deeper with the expectation that it will migrate onshore and nourish the profile. This may be advantageous for the beneficial use of dredge material, which incurs costs or lacks feasibility (due to dredge vessel limitations) when placing sediment in shallower water near the shoreline.

The sediment transport simulated within these idealized scenarios is driven by windwaves alone. This simplification neglects the other drivers of nearshore sediment transport such as tides and winds. Tides modulate the cross-shore surfzone location and winds may generate significant nearshore circulation. Including these forcings would have changed the sediment transport calculations, but they are not the primary driver of nearshore circulation, which is free-surface waves. Since the objective of the study was to examine the influence of nourishment shape/depth on sediment transport and wave attenuation, these other processes were neglected and reserved for future work.

\section{Conclusions}

A numerical model (CMS) coupling phase-averaged wind-waves, nearshore hydrodynamics, and sediment transport/morphological change is used to simulate the evolution of nearshore nourishments and their effects on the wave field. The numerical experiments varied nearshore nourishment shape (linear, undulated, and discrete mounds morphologies), placement depth (i.e., $3 \mathrm{~m}, 5 \mathrm{~m}$, and $7 \mathrm{~m}$ depth), and the wave climate/nearshore 
geomorphology (three coastal regions of the U.S.). A total of 30 idealized cases were simulated and analyzed for inter-comparison.

The analyses elucidate the nearshore nourishments' relative effect on wave energy attenuation, nourishment deflation rates, and cross-shore/alongshore nourishment migration patterns. The primary findings of the analyses were:

1. Shallower placements attenuate more energy than deeper placements for the linear and undulated berms.

2. The linear and undulated berms dissipate more energy than the discrete mounds, in spite of similar placement volumes.

3. The undulated berm dissipates more energy than the linear berm, which is presumably due to its greater alongshore length and may also be influenced by longer lifespans.

4. Longevity analysis shows that placement depth discriminates between continuous and episodic deflation. Shallower placements are subject to more continuous sediment transport, while the deeper placements respond primarily to high-energy events.

5. The trajectories of the modeled nourishments' centers of mass evidences onshoredirected transport of nourishment sediment, which is punctuated by offshore-directed sediment transport due to high-energy, episodic events.

Author Contributions: Conceptualization, C.L.J., B.C.M., D.R.K. and M.E.B.; methodology, C.L.J., B.C.M., D.R.K. and M.E.B.; software, C.L.J. and M.E.B.; formal analysis, C.L.J.; resources, M.E.B.; data curation, C.L.J.; writing-original draft preparation, C.L.J.; Investigation, C.L.J.; writingreview and editing, C.L.J., B.C.M., D.R.K. and M.E.B.; visualization, C.L.J.; supervision, B.C.M.; project administration, B.C.M.; funding acquisition, B.C.M. All authors have read and agreed to the published version of the manuscript.

Funding: This research was funded by the U.S. Army Corps of Engineers Coastal Inlet Research Program (CIRP) through the Inlet Geomorphic Evolution work unit.

Conflicts of Interest: The authors declare no conflict of interest.

\section{References}

1. Houston, J.R. The value of Florida beaches. Shore Beach 2013, 81, 4-11.

2. Elko, N.; Brutsché, K.; Robertson, Q.; Hartman, M.; Dong, Z. USACE Navigation Sediment Placement: An RSM Program Database (1998-2018); CHETN-XX-21; US Army Corps of Engineers Engineer Research and Development Center: Vicksburg, MS, USA, 2021; under review.

3. Ahrens, J.P.; Hands, E.B. Velocity parameters for predicting cross-shore sediment migration. J. Waterw. Port Coast. Ocean Eng. 1998, 124, 16-20. [CrossRef]

4. Bain, R.L.; McFall, B.C.; Krafft, D.R.; Hudson, A. Evaluating transport formulations for application to nearshore berms. J. Waterw. Port Coast. Ocean Eng. 2021, 147, 04021031. [CrossRef]

5. Hands, E.B.; Allison, M.C. Mound migration in deeper water and methods of categorizing active and stable depths. In Proceedings of the Coastal Sediments '91, Seattle, WA, USA, 25-27 June 1991.

6. McFall, B.C.; Brutsché, K.E.; Priestas, A.M.; Krafft, D.R. Evaluation techniques for the beneficial use of dredged sediment placed in the nearshore. J. Waterw. Port Coast. Ocean Eng. 2021, 147, 04021016. [CrossRef]

7. Brutsché, K.E.; McFall, B.C.; Li, H.; McNinch, J.E.; Ousley, J.D.; Engle, J.A.; Maglio, C.K. Strategic nearshore placement of dredged sediment at Vilano Beach, Florida. Shore Beach 2017, 85, 77-84.

8. Huisman, B.J.; Walstra, D.J.R.; Radermacher, M.; de Schipper, M.A.; Ruessink, B.G. Observations and modelling of shoreface nourishment behavior. J. Mar. Sci. Eng. 2019, 7, 59. [CrossRef]

9. van Duin, M.J.P.; Wiersma, N.R.; Walstra, D.J.R.; Van Rijn, L.C.; Stive, M.J.F. Nourishing the shoreface: Observations and hindcasting of the Egmond case, The Netherlands. Coast. Eng. 2004, 51, 813-837. [CrossRef]

10. Brutsché, K.E.; McFall, B.C.; Bryant, D.B. Literature Review of Nearshore Berms; SR-19-2; US Army Corps of Engineers Engineer Research and Development Center: Vicksburg, MS, USA, 2019; 59p.

11. Bryant, D.B.; McFall, B.C. Transport of nearshore dredge material berms. In Proceedings of the 6th International Conference on Application of Physical Modelling in Coastal and Port Engineering and Science, Ottawa, ON, Canada, 10-13 May 2016.

12. Smith, E.R.; Mohr, M.C.; Chader, S.A. Laboratory experiments on beach change due to nearshore mound placement. Coast. Eng. 2017, 121, 119-128. [CrossRef]

13. Li, Y.; Zhang, C.; Cai, Y.; Xie, M.; Wang, Y. Wave Dissipation and Sediment Transport Patterns during Shoreface Nourishment towards Equilibrium. J. Mar. Sci. Eng. 2021, 9, 535. [CrossRef] 
14. Grunnet, N.M.; Walstra, D.J.R.; Ruessink, B.G. Process-based modelling of a shoreface nourishment. Coast. Eng. $2004,51,581-607$. [CrossRef]

15. Hoekstra, P.; Houwman, K.T.; Kroon, A.; Ruessink, B.G.; Roelvink, J.A.; Spanhoff, R. Morphological development of the Terschelling shoreface nourishment in response to hydrodynamic and sediment transport processes. In Proceedings of the 25th International Conference on Coastal Engineering, Orlando, FL, USA, 2-6 September 1996; pp. 2897-2910.

16. Kriauciuniene, J.; Gailiusis, B.; Rimaviciute, E. Modelling of shoreface nourishment in the Lithuanian nearshore of the Baltic Sea. Geologija 2006, 53, 28-37.

17. Kuang, C.; Han, X.; Zhang, J.; Zou, Q.; Dong, B. Morphodynamic Evolution of a Nourished Beach with Artificial Sandbars: Field Observations and Numerical Modeling. J. Mar. Sci. Eng. 2021, 9, 245. [CrossRef]

18. Larson, M.; Ebersole, B.A. An Analytical Model to Predict the Response of Mounds Placed in the Offshore; CHETN-II-42; US Army Corps of Engineers Engineer Research and Development Center: Vicksburg, MS, USA, 1999; 13p.

19. McFall, B.C.; Smith, S.J.; Pollock, C.E.; Rosati, J.; Brutsché, K.E. Evaluating Sediment Mobility for Siting Nearshore Berms; CHETN-IV108; US Army Corps of Engineers Engineer Research and Development Center: Vicksburg, MS, USA, 2016; 11p.

20. Pollock, C.E.; Curtis, W.R.; Moritz, H.R. Numerical Methods for Nearshore-Berm Evaluation, St. Johns County, Florida; CHL-98-12; US Army Corps of Engineers Engineer Research and Development Center: Vicksburg, MS, USA, 1998; 131p.

21. Priestas, A.M.; McFall, B.C.; Brutsche, K.E. Performance of Nearshore Berms from Dredged Sediments: Validation of the Sediment Mobility Tool; TR-19-19; US Army Corps of Engineers Engineer Research and Development Center: Vicksburg, MS, USA, 2019; 63p.

22. Zhang, J.; Larson, M. A numerical model for offshore mound evolution. J. Mar. Sci. Eng. 2020, 8, 160. [CrossRef]

23. Brutsché, K.; Pollock, C.E. Strategic Placement of Mixed Sediment in the Form of a Nearshore Berm along Fort Myers Beach, Florida; TN-EWN-17-1; US Army Corps of Engineers Engineer Research and Development Center: Vicksburg, MS, USA, 2017; 3p.

24. Dolan, R.; Donoghue, C.; Stewart, D. Long-term Impacts of Tidal Inlet Bypassing on the Swash Zone Filter Feeder Emerita talpoida Oregon Inlet and Pea Island, North Carolina. Shore Beach 2006, 74, 23-27.

25. Dolan, R.; Stewart, D. A concept for reducing ecological impacts of beach nourishment and tidal inlet bypassing. Shore Beach 2006, $74,28-31$.

26. Young, D.L.; Brutsché, K.E.; Li, H.; McFall, B.C.; Maloney, E.C.; McClain, K.E.; Bucaro, D.F.; LeRoy, J.Z.; Dunker, J.J.; Johnson, K.K.; et al. Analysis of Nearshore Placement of Sediments at Ogden Dunes, Indiana; TR-20-4; US Army Corps of Engineers Engineer Research and Development Center: Vicksburg, MS, USA, 2020; 98p.

27. Figlus, J.; Song, Y.-K.; Maglio, C.K.; Friend, P.L.; Poleykett, J.; Engel, F.L.; Schoenblen, D.; Boburka, K. Particle Tracer Analysis for Submerged Berm Placement of Dredged Material Near South Padre Island, Texas. WEDA J. Dredg. 2021, 19, 14-30.

28. Brutsché, K.E.; McFall, B.C.; Li, H.; McNinch, J.E.; Ousley, J.D.; Engle, J.A.; Maglio, C.K. Strategic Placement of Dredge Material in Vilano Beach, Florida, USA. In Proceedings of the Coastal Sediments 2019: Proceedings of the 9th International Conference, St. Petersburg, FL, USA, 27-31 May 2019; pp. 2793-2804.

29. Bryant, M.A.; Hesser, T.J.; Jensen, R.E. ERDC/CHL CHETN-I-91; U.S. Army Engineer Research and Development Center: Vicksburg, MS, USA, 2016.

30. McFall, B.C. The Relationship between Beach Grain Size and Intertidal Beach Face Slope. J. Coast. Res. 2019, 35, 1080-1086. [CrossRef]

31. De Masi, G.; Bruschi, R.; Drago, M. Synthetic Metocean Time Series Generation for Offshore Operability and Design Based on Multivariate Markov Model; MTS/IEEE OCEANS; Discovering Sustainable Ocean Energy for a New World: Genova, Italy, 2015.

32. Militello, A.; Reed, C.W.; Zundel, A.K.; Kraus, N.C. Two-Dimensional Depth-Averaged Circulation Model M2D: Version 2.0, Report 1, Technical Documentation and User's Guide; TR-04-2; U.S. Army Engineer Research and Development Center: Vicksburg, MS, USA, 2004; 131p.

33. Reed, C.W.; Brown, M.E.; Sanchez, A.; Wu, W.; Buttolph, A.M. The Coastal Modeling System Flow Model (CMS-Flow): Past and Present. J. Coast. Res. 2011, 59, 1-6. [CrossRef]

34. Sanchez, A.; Wu, W.; Li, H.; Brown, M.; Reed, C.; Rosati, J.D.; Demirbilek, Z. Coastal Modeling System: Mathematical Formulations and Numerical Methods; TR-14-2; U.S. Army Engineer Research and Development Center: Vicksburg, MS, USA, 2014; 87p.

35. Sanchez, A.; Wu, W.; Beck, T.M. A depth-averaged 2-D model of flow and sediment transport in coastal waters. Ocean Dyn. 2016, 66, 1475-1495. [CrossRef]

36. Lin, L.; Demirbilek, Z.; Mase, H.; Zheng, J.; Yamada, F. CMS-Wave: A Nearshore Spectral Wave Processes Model for Coastal Inlets and Navigation Projects; TR-08-13; U.S. Army Engineer Research and Development Center: Vicksburg, MS, USA, 2008; 132p.

37. Wu, W.; Sánchez, A.; Zhang, M. An implicit 2-D shallow water flow model on an unstructured quadtree rectangular grid. J. Coast. Res. 2011, 59, 15-26. [CrossRef]

38. Lin, L.; Demirbilek, Z.; Mase, H. Recent capabilities of CMS-Wave: A coastal wave model for inlets and navigation projects. J. Coast. Res. 2011, 59, 7-14. [CrossRef]

39. Camenen, B.; Larson, M. A General Formula for Non-Cohesive Suspended Sediment Transport. J. Coast. Res. 2008, 24, 615-627. [CrossRef]

40. Brutsché, K.E.; Wang, P.; Beck, T.M.; Rosati, J.D.; Legault, K.R. Morphological evolution of a submerged artificial nearshore berm along a low-wave microtidal coast, Fort Myers Beach, west central Florida, USA. Coast. Eng. 2014, 91, 29-44. [CrossRef] 